Marquette University

e-Publications@Marquette

$10-1-2015$

\title{
The Impacts of Elicitation Mechanism and Reward Size on Estimated Rates of Time Preference
}

Andrew G. Meyer

Marquette University, andrew.meyer@marquette.edu

NOTICE: this is the author's version of a work that was accepted for publication in Journal of Behavioral and Experimental Economics. Changes resulting from the publishing process, such as peer review, editing, corrections, structural formatting, and other quality control mechanisms may not be reflected in this document. Changes may have been made to this work since it was submitted for publication. A definitive version was subsequently published in Journal of Behavioral and Experimental Economics, Vol. 58, (October 2015): 132-148. DOI. (C) 2015 Elsevier. Used with permission. 


\title{
The Impacts of Elicitation Mechanism and Reward Size on Estimated Rates of Time Preference
}

\author{
Andrew Meyer*
}

August 7, 2015

*Assistant Professor, Department of Economics, Marquette University, Milwaukee, WI, andrew.g.meyer@marquette.edu, 414-288-5489 


\begin{abstract}
[The Impact of Elicitation Mechanism and Reward Size on Estimated Rates of Time Preference]

We run experiments with real monetary rewards ranging from $\$ 10$ to $\$ 500$ to estimate rates of time preference and test for hyperbolic discounting. Individuals become more patient with increasing reward sizes, which is consistent with a magnitude effect. This magnitude effect is robust across specifications including a nonparametric analysis and structural maximum likelihood estimation. Subjects are divided between two different elicitation mechanisms (one a matching task and one a choice task) that should both theoretically provide an incentive for participants to reveal their true time preferences. We find some evidence of differences between the rates from the matching and choice tasks but these differences disappear when appropriately modeling the behavioral noise. We uncover little to no evidence of present-biased time preferences.
\end{abstract}

JEL Classification: D90, C91, D03

Keywords: discounting, intertemporal choice, experiments, magnitude effect

*This work was supported in part by a grant titled, "Evaluation of Preferences for Land Management Options," from the USDA National Forest Service.

*We thank participants at the 2013 Annual Summer Meetings of the Association of Environmental and Resource Economists in Banff, AB for helpful comments on this research.

*We thank two anonymous reviewers and the editor for helpful comments that have improved the quality of the paper.

*We thank Glenn Harrison for sharing sample Stata code and for helpful comments concerning estimation of the random coefficients models. 


\section{Introduction}

Decisions involving tradeoffs over time are ubiquitous in our daily lives. According to economic theory, individual rates of time preference (discount rates) determine how individuals compare alternatives across time. In order to discern how individuals make decisions over alternatives with distinct temporal profiles we must have an improved understanding of individuals' discount rates. The most popular way to estimate discount rates is to use data from the experimental laboratory. This raises the concern that aspects of the experimental design may significantly influence our estimates. To investigate this issue, we develop experiments with real monetary rewards that utilize several magnitudes of rewards and two different mechanisms to elicit discount rates. One of the elicitation mechanisms is a choice based variant of the Becker-DeGroot-Marschak (hereafter BDM) (Becker et al., 1964) mechanism and the other is a variant of an open-ended fill-in-the-blank second-price sealed bid / Vikrey (hereafter 2PSB) (Vickrey, 1961) auction. Overall, we find little evidence of present-biased time preferences. However, the average individual appears to be more present-biased when making decisions over small monetary rewards. Furthermore, consistent with a magnitude effect, the stakes of the reward substantially change the estimated annual discount rate. We find some evidence that the elicitation mechanism matters for our estimates, but differences disappear when we structurally model the intertemporal utility function in a maximum likelihood framework.

Previous experimental discounting studies have been criticized on several grounds (Frederick et al. (2002); Andreoni and Sprenger (2012a); Andreoni and Sprenger $(2012 b)$ ). First, the rewards are often hypothetical rather than real so we may be concerned about potential hypothetical bias. Second, when researchers do employ real rewards, they are often quite small in magnitude. This can be problematic for at least two reasons-transaction costs and rounding. Participants may incorporate the transaction cost of acquiring a future reward into their decision-making. We will increasingly overestimate exponential discount rates as the size of the perceived transaction cost increases relative to the magnitude of the reward because, with smaller reward sizes, the transaction cost of retrieving one's future reward is larger relative to the reward size, and with larger rewards, the transaction cost of retrieving one's future reward is small compared to the reward size. Furthermore, if transaction costs are perceived to be larger for future rewards than for immediate rewards, an exponential discounter can appear to be present-biased. It also appears that participants often utilize rounding when performing discounting tasks, which can explain why es- 
timated rates are often significantly higher for smaller stakes (Andersen et al., 2013). Third, many previous studies do not have experimental designs that facilitate the testing of hyperbolic discounting. Finally, not many experimental discounting studies have examined the impact of specific elicitation mechanisms. This leaves open the possibility that previous findings are at least partially explained by the specific mechanism, which could potentially mask pure time preferences. For example, Andersen et al. (2013) note that "we strongly encourage systematic studies of the effects of using choice and open-ended fill-in-the-blank procedures." We implement an experimental design in which real monetary rewards vary from $\$ 10$ to $\$ 500$ across two different elicitation methods (one choice and one open-ended) that should theoretically be incentive compatible. Furthermore, the experimental design incorporates a front end delay in some of the experimental rounds so that we can test for hyperbolic discounting.

With a subject pool of 76 participants, we estimate aggregate discount factors and test for hyperbolic discounting. Several interesting results emerge. Most strikingly, and one of the main contributions of this paper, we find that the size of the reward can substantially change the estimated present-bias and the estimated annual discount rate. For the case of linear utility and using our preferred maximum likelihood estimates, the average predicted annual discount rate decreases by approximately $31 \%$ for a choice with a reference magnitude of $\$ 100$ compared to choice with a reference magnitude of $\$ 10$. This suggests that results from laboratory experiments with very small rewards should be interpreted cautiously.

Researchers apply BDM mechanisms in the experimental economics literature because of their desirable incentive compatibility. We show that a specific BDM mechanism can also be used in the context of discounting experiments to provide the incentive for participants to reveal their true intertemporal preferences. 2PSB auctions are also widely utilized since it is a weakly dominant strategy in a 2PSB auction to bid one's true value. Again, we show that a specific 2PSB mechanism incentivizes participants to reveal their true intertemporal preferences. It then follows that any differences in the patterns of discounting between the two mechanisms would suggest that one of the mechanisms is confounding our estimates. However, as the second main contribution of this paper, we find that the method of elicitation matters only for the estimation strategies that do not adequately account for the differences in the behavioral noise between the two mechanisms. Once modeling the intertemporal utility functions in a maximum likelihood framework along the lines of Andersen et al. (2008), which explicitly addresses the behavioral noise parameters, we do not 
find significant differences between the two mechanisms.

Andersen et al. (2008) and Andreoni and Sprenger (2012a) have recently shown that the curvature of the utility function is important when estimating discount rates. To get a sense of the curvature implications for this application, we examine results using the concavity parameters from their work. Using a CRRA utility function, we examine discounting results for the curvature parameters of 0.92 as found in Andreoni and Sprenger (2012a) and 0.259 as implied in Andersen et al. (2008). For the curvature parameter of 0.92 , average annual discount rates from the maximum likelihood results are predicted to be approximately $26 \%$ lower for the $\$ 100$ reward choices compared to the $\$ 10$ reward choices. For the curvature parameter of 0.259 , average annual discount rates from the maximum likelihood framework decrease by around $18.5 \%$ for a $\$ 100$ reward compared to a $\$ 10$ reward. Thus, our findings of a magnitude effect are robust to the assumptions on utility curvature.

\section{Related Literature}

The two bodies of literature relevant to the study at hand are the literature on auction mechanisms in experimental economics and the literature on time preferences. The BDM and 2PSB mechanisms have long histories of use in experimental economics papers. ${ }^{1}$ They are popular because of their incentive compatibility; bidders maximize utility by revealing their true valuations in both mechanisms. Thus, theoretically, we would expect to find similar results from both mechanisms. However, there is evidence that the two mechanisms produce different results in certain contexts. Braga and Starmer (2005) review several studies where preference anomalies persist with BDM mechanisms but are eroded away with other elicitation mechanisms such as the 2PSB mechanism. Several studies find different results when using the BDM and secondprice mechanisms in the context of the willingness to pay (WTP) / willingness to accept (WTA) gap. The seminal paper by Kahneman et al. (1990) finds an endowment effect using the BDM mechanism. But, then Shogren et al. (1994) find no evidence of an endowment effect using a second-price auction. Shogren et al. (2001) find that, while both mechanisms initially produce results consistent with the endowment effect, the gap disappears in later rounds for the second-price auctions. Similarly, in inducedvalue experiments, Noussair et al. (2004) find that subjects bid closer to their true values and converge to their true values quicker with the $2 \mathrm{PSB}$ auction than with the

\footnotetext{
${ }^{1}$ We do not review all BDM and 2PSB experiments here but note that a review of experimental studies prior to 2004 is found in Noussair et al. (2004).
} 
BDM mechanism. In summary, there is some evidence that the 2PSB auction may produce fewer anomalies in a variety of contexts. However, Cason and Plott (2014) take a different stand on the issue. They find that subjects systematically make mistakes in the BDM due to a failure of game form recognition, and therefore conclude that inferences about non-standard preferences from BDM data can be misguided.

There is an extensive literature on time preferences in both economics and psychology. We focus here on two aspects of the time preference literature including the effects of different elicitation mechanisms and the magnitude effect. There are two general elicitation approaches utilized in experimental studies of time preferenceschoice and matching tasks (Hardisty et al., 2013). Matching tasks require individuals to equate different sized rewards received at different time periods. Subjects in choice tasks typically make binary choices between a series of earlier and later rewards. One particular type of choice task, the multiple price list (MPL) approach has become the most common mechanism for estimating discount rates. MPLs ask individuals to make repeated choices between smaller more proximate rewards and larger more distant rewards. Then, the point where an individual switches from preferring the more proximate reward to the reward further in the future provides interval information about time preferences. Two notable examples of the MPL approach are Coller and Williams (1999) and Harrison et al. (2002). Harrison et al. (2002) find an overall individual discount rate in Denmark of 28.1 percent and Coller and Williams (1999) find a discount rate of $15-25 \%$. One criticism of the MPL is that the imposition of linear preferences creates an upwards bias in estimates of the discount rate. In response, two different methods have been recently proposed. The Andersen et al. (2008) approach has respondents make MPL choices over risky outcomes to simultaneously estimate risk and time preferences and find a discount rate of about 10 percent. The Andreoni and Sprenger (2012a) convex time budget (CTB) approach has respondents allocate tokens from convex budgets to identify discounting and utility curvature parameters. They find average discount rates of about 30 percent from this method.

Several studies have compared the estimated time preferences from choice and matching tasks. Hardisty et al. (2013) compare discount rates from the two types of tasks and find evidence that the elicitation mechanism does matter. Rates from the choice-based methods are generally higher than the rates from the matching tasks. Hardisty et al. (2013) attributes the differences to the framing inherent in the range of implicit rates offered to participants during matching tasks. Manzini et al. (2008) compare results from a MPL method, a BDM method, and a 2PSB auction mechanism. The BDM utilized in Manzini et al. (2008) solicits bids in 
an open-ended manner so that both the BDM and 2PSB mechanisms are matching tasks. They find no significant differences between the BDM and 2PSB rates, but find higher rates from the MPL method compared to rates from the BDM or 2PSB. Several other studies similarly find that matching tasks lead to lower inferred discount rates relative to choice tasks (Ahlbrecht and Weber, 1997; Read and Roelofsma, 2003). In examining MPL and CTB data, Chakraborty et al. (2015) find that the two elicitation mechanisms produce different results.

In general, discount rates estimated in experiments have mostly been much higher than the interest rates that we see in financial markets (Frederick et al., 2002). One explanation for the high estimated experimental discount rates is the magnitude effect. The magnitude effect is "the finding that smaller amounts are discounted more than larger amounts" (Andersen et al., 2013). Since experimental studies typically use small stakes, on the order of $\$ 10$, the high estimated discount rates may not be indicative of the rates that we would see in real world choices with much larger stakes. Various studies document evidence of a substantial magnitude effect. Andersen et al. (2013) provide a comprehensive review of these studies, noting that the magnitude effect appears to be a robust finding across studies with hypothetical and real rewards. We focus here on several of the most recent studies. Benhabib et al. (2010) find evidence of a fixed cost of discounting, rather than quasi-hyperbolic discounting. This is consistent with a magnitude effect, in that increasing the size of the reward should decrease the estimated discount rate. Halevy (2015) examines average switching points from choices between sooner and later rewards with stakes of $\$ 10$ and $\$ 100$; reported point estimates imply rates that are several times higher for the small stakes compared to the large stakes. However, the magnitude effect is not uniformly found to be substantial. Andersen et al. (2013) examine binary choice data from Denmark using two reward sizes of 1500 and 3000 kroner (roughly $\$ 300$ to $\$ 600$ US). They find a statistically significant magnitude effect, but the scale of the effect is much smaller than that found in other studies. Finally, Manzini et al. (2008) do not find evidence of a magnitude effect; there are no significant differences between discounting rates from low stakes $(20 €)$ tasks and high stakes $(50 €)$ tasks.

In contrast to the traditional exponential discounting model which produces an estimate of one constant marginal discount rate, various hyperbolic discounting models have been proposed and tested in more recent literature. Hyperbolic models are motivated by the observation in some empirical studies of declining marginal discount rates. That is, individuals sometimes become more patient for choices far in the future than they are for choices involving the present. The exponential discounting model, 
also called the discounted utility (DU) model, is attributed to Samuelson (1937) and states that intertemporal utility from consumption bundles in time periods 0 (now) through $T$ is given by

$$
U\left(c_{0}, c_{1}, \ldots, c_{T}\right)=\sum_{t=0}^{T} \psi_{t} u\left(c_{t}\right)
$$

where the discount factor for year $t$ is $\psi_{t}=\left[\frac{1}{1+\rho}\right]^{t}$ and $\rho$ is the discount rate. Common hyperbolic specifications include the Harvey (1986) model, the Herrnstein (1981) and Mazur (1987) model, and the quasi-hyperbolic $(\beta, \delta)$ discounting model. The quasihyperbolic functional form was first introduced by Phelps and Pollak (1968) in the context of intergenerational altruism and further studied by Laibson (1997). The functional form is given by

$$
\psi_{t}=\left\{\begin{array}{c}
1 \text { if } t=0 \text { and } \\
\beta \delta^{t} \text { if } t>0
\end{array}\right\} \text {, where } 0<\beta<1 \text {, and } \delta<1
$$

Note that the only difference between the exponential discounting model and the quasi-hyperbolic model is the $\beta$ term which typically is interpreted as the presentbias parameter.

Several studies find evidence of hyperbolic discounting at the individual level, including Kirby and Marakovic (1995), Slonim et al. (2007), Cairns and van der Pol (2000), and Keller and Strazzera (2002). Andreoni and Sprenger (2012a) test for hyperbolic discounting but do not find evidence to reject the exponential model. They speculate that potential reasons for this could include their efforts to equate transaction costs across immediate and future payoffs and to reduce uncertainty in the delivery of future rewards. They also note that researchers should not expect to find present-bias in experiments with monetary rewards if subjects have access to liquidity. Likewise, Andersen et al. (2014) fail to find evidence of quasi-hyperbolic or fixed cost discounting in a representative sample of adult Danes.

\section{Incentive Compatibility for Discounting Exper- iments}

As previously stated, we utilize two mechanisms for this experiment. One is a variant of the BDM mechanism and the other is a variant of the Second Price Sealed Bid Auction. Here, we describe the basic setup of each mechanism and note that we 
would theoretically expect both mechanisms to produce similar results because both mechanisms provide the incentive to reveal one's true time preferences. ${ }^{2}$

\subsection{BDM Mechanism}

In the BDM mechanism, participants are instructed the following. "You have the chance to receive $\$ \mathrm{x}$ now or another sum of money $t$ time periods from today. Please indicate for which dollar amounts you would choose to receive the more delayed reward (and no payment now) and for which dollar amounts you would choose to receive $\$ \mathrm{x}$ now (and no money at time period $t$ ).

After you have made your selections one dollar amount will be randomly selected to determine the amount of the reward at time $t$. If you have indicated that you would choose the delayed reward at that dollar amount I will pay you the selected dollar amount $t$ time periods from now. If you have indicated that you would not choose the delayed reward at that dollar amount I will pay you \$x now."

\subsection{Second Price Sealed Bid Mechanism}

In the 2PSB mechanism, participants are instructed the following. "You have the chance to receive $\$ \mathrm{x}$ today or another sum of money in the future. For each of the delays listed below, indicate how much money you would be willing to accept at that time instead of $\$ x$ today.

$\mathrm{t}$ time periods from today

$\mathrm{t}+1$ time periods from today

$\mathrm{t}+2$ time periods from today

(etc.)

One delay will be chosen at random. The person with the lowest bid for that time period will win the delayed reward. They will win an amount equal to the second lowest bid for the chosen time period. Everybody else will get the immediate reward of $\$ \mathrm{x} . "$

\section{Experimental Design and Data}

We ran 11 separate experimental sessions, for a total of 76 student participants. Sessions were split between two universities (University of Colorado-Boulder and

\footnotetext{
${ }^{2}$ Proofs are provided in the Appendix.
} 
Ohio Wesleyan University) and run between spring 2009 and spring 2012. ${ }^{3}$ Subjects participated in either a BDM session or a $2 \mathrm{PSB}$ session. Table 1 summarizes the details of the experimental sessions. 38 of the subjects participated in 2PSB sessions whereas 34 participated in BDM sessions. All sessions were designed to include 8 subjects and had 8 subjects register to participate in each session. Due to no-shows, the median session size was 7 individuals.

\subsection{Recruitment}

Student participants were recruited in several ways. The Psychology Department of The University of Colorado-Boulder (hereafter CU) has a paid research system where the study was advertised. Interested students would then electronically reserve a spot in the experiment. At Ohio Wesleyan University (hereafter OWU), we did not have access to a similar system so subjects were recruited by announcements in Principles of Economics courses and flyers placed in academic buildings. ${ }^{4}$ All subjects were undergraduate students. Only subjects planning to remain students on campus for at least six more months were allowed to participate. The latest payment options were delivered six months after the experiment so we wanted to avoid the potential extra transaction costs or uncertainty in the receipt of the reward that could confound time preference results when students graduate or move.

\subsection{Protocol}

The sessions began with the experimenter explaining that this was an experiment in individual decision-making and explaining the basic outline of the session. Each subject was given a paper script with directions and an identification number. Subjects were informed that no identifying information would be collected and that results would remain anonymous. Next, the experimenter explained the rules of the mechanism (BDM or 2PSB) and the rules that would determine the take-home pay of the experiment. In short, the experimenter explained that the take-home pay would depend upon the outcomes of the binding rounds of the experiment, a random draw to

\footnotetext{
${ }^{3}$ Ideally, all experimental sessions would have been run within a shorter time-frame and at the same location. A combination of factors, including poor turnout to several sessions at University of Colorado-Boulder, budget constraints, and a change in institutional affiliation led to the time delays. We later include an indicator variable for institution in the empirical analysis and find no difference between the discount rates.

${ }^{4}$ Principles of Economics is a popular course at OWU. It sees a diverse student population because it fulfills several general education requirements and it is the entry course for any student who would be interested in economics or business topics.
} 
determine which binding round's results would be used and a random draw to determine which participant would get paid according to the results of the selected binding round. All subjects received at least a $\$ 10$ participation fee. One participant in each session was paid according to the results of a binding round. Since the random draws were at the end of the experiment, participants did not know ex ante whether they would be paid the $\$ 10$ participation fee or according to one of the binding rounds. This allowed us to use larger reward sizes with our budget while maintaining the consequentiality of the binding rounds. The experimenter conducted three hypothetical rounds to illustrate the rules of the mechanism. For both the BDM and 2PSB mechanisms, the first hypothetical round did not involve any time dimension. It was simply intended to teach the subjects that it is in their best interest to reveal their true valuations in these mechanisms. The second and third hypothetical rounds introduced the time dimension of the mechanisms. The experimenter encouraged questions during these hypothetical rounds and clarified any misunderstandings at that time. In each session, the experimenter made sure each participant understood the rules of the mechanism before proceeding to the binding rounds. There was no written nor verbal communication permitted among participants during the binding rounds. Similarly, the experimenter did not communicate with participants during binding rounds other than to read the script. Finally, the experimenter collected basic demographics including age, gender, race/ethnicity, employment status, and personal income subsequent to the binding rounds. The total time involved for each session ranged from about 45 minutes to one hour. The same experimenter conducted all experimental sessions.

\subsubsection{BDM Details}

Each binding round of the BDM sessions followed the same script. The only things that changed across the rounds and sessions were the reference payment amount (\$10, $\$ 50, \$ 100$, or $\$ 500)$, the reference time period (now, one month from now), and the length of the interval between payment options (one month, two months, five months, six months). ${ }^{5}$ Depending on the session, subjects completed between four and six binding rounds. For each round of the session, each subject selected all of the payment options for which they would prefer the immediate payment and all of the payment options for which they would prefer the future payment. The future payment options increase monotonically, so that the switching point between the immediate reward and the future reward reveals information about the subject's

\footnotetext{
${ }^{5}$ See the appendix for the complete BDM script for one of the rounds.
} 
time preferences. Thus, we have one observation from each round of each session, for each individual.

\subsubsection{PSB Details}

Like the BDM sessions, each binding round of the 2PSB sessions followed the same script. Only the reference payment amount, reference time period, and interval length changed across the rounds and sessions. ${ }^{6}$ Depending on the session, subjects completed between four and eight binding rounds. We note that the BDM mechanism utilized herein would be considered a choice task whereas the 2PSB method would be considered a matching task.

\subsubsection{Experimental Payments}

It is important to minimize transaction costs across payments and minimize uncertainty in the payment of future rewards. Failure to adequately address transaction costs or uncertainty could cause the experimenter to observe hyperbolic discount rates even when the individual is truly an exponential discounter. For future payments, subjects were allowed to choose between two cash options at both locations, in-person or via the postal service. At CU, subjects could choose to pick up the future reward in the Economics department from the experimenter or from the Department Chair so this lent extra credibility to the future payment. At OWU, they could either choose to pick up a future reward in the Economics department from the experimenter or the department secretary. In both locations, subjects could choose to have a payment mailed to an off-campus address. The experimenter brought envelopes to each session so that subjects could self-address the envelope in the case that they chose to receive a future payment via the postal service. The rationale for providing two options for the future payments was to minimize the transaction cost of those payments, assuming that the participant would choose whichever option would minimize their individual transaction costs. Immediate payments were delivered in cash at the end of the experimental session. The experimenter brought cash to each experimental session and showed it to the subjects, demonstrating that the cash rewards would in fact be delivered.

\footnotetext{
${ }^{6}$ See the appendix for the complete 2 PSB script for one of the rounds.
} 


\section{$5 \quad$ Empirical Results}

\subsection{Description of Discounting Distributions}

We begin by describing the individual choices from each round and each individual who participated in the BDM and 2PSB mechanisms. Here, instead of estimating parameters from an econometric model, we describe the (exponential) discount rate that is directly implied by an individual's choice for a given round. One benefit of this approach is that it imposes minimal structural assumptions. Another benefit is that it gives us an idea of the heterogeneity in discount rates across individuals and choices. Participants in both mechanisms are induced with a reference dollar amount. BDM participants then reveal an interval for the equivalent future value of a delayed reward while $2 \mathrm{PSB}$ participants reveal one number for the equivalent future value of the delayed reward. Denote the reference reward at time $t$ as $c_{t}$ and the future value of the delayed reward at time $t+k$ as $c_{t+k}$. Then, the annual exponential discount rate, $\rho^{7}$, implied by a choice in the $2 \mathrm{PSB}$ mechanism is given by

$$
\rho=\left(\frac{c_{t+k}}{c_{t}}\right)^{(12 / k)}-1
$$

For BDM participants, denote the lower bound of the interval of the future value of the delayed reward as $l b_{t+k}$ and the upper limit of the interval of the future value of the delayed reward as $u b_{t+k}$. Then, we approximate $\rho$ implied by a choice in the BDM mechanism with

$$
\rho=\frac{\left[\left(\frac{l b_{t+k}}{c_{t}}\right)^{(12 / k)}-1\right]+\left[\left(\frac{u b_{t+k}}{c_{t}}\right)^{(12 / k)}-1\right]}{2} .
$$

Table 2 describes the distribution of discount rates for the full sample. We also describe the distributions of rates from the BDM and 2PSB mechanism subsamples and by reference dollar amount. There is clearly a range of implied discount rates in Table 2; the annual rate at the 25th percentile of the full sample is $13.4 \%$ and at the 98 th percentile is $394,900 \%$. However, it is also clear that most of the incredibly high rates are coming from the $\$ 10$ and $\$ 50$ reference reward levels. In general, it seems that the implied rates decline substantially with reward size, consistent with a magnitude effect. The rates from the BDM mechanism also seem to be higher than the corresponding rates from the 2PSB mechanism. The mean discount rates

\footnotetext{
${ }^{7}$ This implicitly assumes linear utility.
} 
are incredibly large compared to their median counterparts suggesting influence of outliers. Therefore, we next remove the top $5 \%$ of observations from the full sample to see how the distribution differs with the exclusion of these outliers. As seen in the lower half of Table 2, as would be expected, the median rate of the remaining observations $(77.2 \%)$ does not differ substantially from the median of the full sample (79.6\%). However, the means decrease by orders of magnitude. There is a more noticeable change in the distribution of the BDM observations when excluding outliers compared to the $2 \mathrm{PSB}$ observations. As for the 17 observations that are removed as part of the top 5 percentile, 11 come from the $\$ 10$ reward level, 2 come from the $\$ 50$ reward level, and 4 come from the $\$ 100$ reward level. Moreover, 5 of the 17 highest observations are from the 2PSB mechanism and 12 are from the BDM mechanism.

We next conduct Komogorov-Smirnov tests for equality of distribution functions. We compare the distribution of BDM rates to the distribution of $2 \mathrm{PSB}$ rates and we compare the distribution of small reference dollar reward ( $\$ 10$ and $\$ 50)$ rates to the distribution of large reference dollar reward $(\$ 100$ and $\$ 500)$ rates. From these tests, we conclude that the $2 \mathrm{PSB}$ mechanism contains smaller values than the BDM mechanism $(\mathrm{p}$-value $=0.000)$ and that the large reference dollar reward contains smaller values than the small reference dollar reward ( $\mathrm{p}$-value $=0.000) .{ }^{8}$ Thus, this analysis overall suggests that the 2PSB mechanism produces smaller discount rates than the BDM mechanism and that there is a significant magnitude effect.

Given the apparent differences in the rates from the two mechanisms, we may wonder which mechanism produces results that are "more correct." One way to select between the two mechanisms is to test internal consistency ${ }^{9}$; a test that researchers use to assess internal consistency is Cronbach's alpha (Cronbach, 1951). In our application, this could be used to see if inferred discount rates represent the same underlying latent construct across the rounds for a given session of each mechanism. One problem with using such a measure is that it also appears that the magnitude of the reward matters for the size of the estimated discount rate. Each individual completes rounds with varying magnitudes of the reward, and there is no case where one individual sees all of the possible magnitudes. Thus, we would expect Cronbach's alpha to be lower for sessions where the variance of the magnitude of the rewards is higher, regardless of elicitation mechanism. Nonetheless, given that the reward sizes are approximately balanced across the two mechanisms, we calculate Cronbach's alpha for each session using the inferred rates as summarized in Table 2. The average value for the BDM

\footnotetext{
${ }^{8}$ The same is true for the subsample that excludes the top $5 \%$ of observations from the full sample.

${ }^{9}$ We thank an anonymous reviewer for this suggestion.
} 
sessions is 0.25 and for the $2 \mathrm{PSB}$ sessions is 0.41 . However, when we exclude the top $5 \%$ of all observations, the alpha values become much closer; BDM rounds average 0.55 and 2PSB rounds average 0.595. This suggests that the BDM may be more prone to extreme observations, but in absence of the outliers, the mechanisms have approximately the same internal consistency.

There are several drawbacks to this approach of analyzing the data. First, we are implicitly assuming that individuals do not make behavioral errors during the discounting tasks. This is potentially a dangerous assumption because behavioral errors may differ across the elicitation mechanisms and/or across the reference dollar magnitudes. Also, the approximation of $\rho$ from the BDM interval data is not satisfying because it overstates our precision in those estimates. Another drawback is that we are not able to test for a present-bias or hyperbolic discounting in this description of the discounting distributions. Finally, it is not possible to explain systematic differences in discount rates due to observable characteristics. In light of these shortcomings, we present results from several other estimation strategies.

\subsection{Econometric Model to Test for Present-bias}

Here, we develop a basic econometric model that can test for quasi-hyperbolic discounting. Recall that we do not have an experimental design that facilitates the estimation of utility curvature parameters. Nevertheless, we can take estimates from other studies as given for sensitivity analysis. Therefore, following Andreoni and Sprenger (2012a) and Andersen et al. (2008), we specify a time separable CRRA utility function,

$$
U\left(c_{t}, c_{t+k}\right)=u\left(c_{t}\right)+\beta \delta^{k} u\left(c_{t+k}\right)=c_{t}^{\alpha}+\beta \delta^{k} c_{t+k}^{\alpha}
$$

where $\alpha$ is the CRRA curvature parameter, $k$ is the interval (measured in months), $\beta$ is the parameter to capture any present-bias, and $\delta$ is the monthly discount factor. ${ }^{10}$ Next, note that an individual with this utility function who is indifferent between two dollar amounts received at two different times would satisfy the condition,

$$
c_{t}^{\alpha}=\left\{\begin{array}{c}
\beta \delta^{k} c_{t+k}^{\alpha} \text { if } t=0, \text { and } \\
\delta^{k} c_{t+k}^{\alpha} \text { if } t>0
\end{array}\right\} .
$$

\footnotetext{
${ }^{10}$ Note that $\delta=\left(\frac{1}{1+\rho}\right)^{1 / 12}$, where $\rho$ is the annual discount rate.
} 
Rearranging, we have

$$
\frac{c_{t}}{c_{t+k}}=\left\{\begin{array}{c}
\left(\beta \delta^{k}\right)^{1 / \alpha} \text { if } t=0, \text { and } \\
\left(\delta^{k}\right)^{1 / \alpha} \text { if } t>0
\end{array}\right\} \text {. }
$$

Finally, we log-linearize the equation and append an error term to create the econometric model,

$$
\ln \left(\frac{c_{t}}{c_{t+k}}\right)=\frac{\ln \beta}{\alpha} I_{t=0}+\frac{\ln \delta}{\alpha} k+\varepsilon
$$

where $I_{t=0}$ is an indicator variable for time period $t=0$. We know the reference dollar amount, $c_{t}$, for each discounting choice because we set this. Participants reveal the delayed payment equivalent, $c_{t+k}$, in the 2 PSB experiments but reveal an interval for $c_{t+k}$ in the BDM experiments. Therefore, we use an interval regression to estimate equation 6 . For the assumption of linear utility, $\alpha=1$. We explore various values of $\alpha$ to examine the implications for the discount rate. We clearly do not get direct estimates of $\beta$ or $\rho$; it is necessary to take nonlinear combinations of parameter estimates.

Denote the estimated coefficient on $I_{t=0}$ as $b_{I_{t=0}}$ and the estimated coefficient on $k$ as $b_{k}$. Then, $\beta$ is estimated by $e^{\alpha b_{I}=0}$. Similarly, $\rho$ is estimated by $\left(\frac{1}{e^{\alpha * b_{k}}}\right)^{12}-1$. Standard errors are calculated using the delta method. ${ }^{11}$ Table 3 presents discounting results from this model with all data pooled together under a variety of assumptions on $\alpha$. For linear utility, the mean annual discount rate is estimated at $130.2 \%$, and the present-bias parameter, $\beta$, is significantly different from 1 . However, the magnitude of the present-bias is not substantial; the point estimate of the marginal annual discount rate between now and one year from now is $\frac{1}{\widehat{\beta}} *(1+\widehat{\rho})-1=138.3 \%$ whereas the marginal annual discount rate between any two future years is $130.0 \%$. The magnitude of the estimated discount rate decreases as $\alpha$ decreases, as we would expect.

Table 4 presents discounting results when the sample is restricted to the $\$ 10$ immediate payment option and Table 5 shows results when the sample is restricted to the larger dollar amounts. While, at first glance the point estimates appear different between the two tables, neither model finds $\beta$ to be significantly different from 1 . Also, the confidence intervals on the estimates of $\rho$ are overlapping. However, Tables 4 and 5 may indicate that some of the present-bias found in the pooled data (Table 3 ) is being driven by the $\$ 10$ rounds. The point estimate of $\beta$ is around 0.89 in Table 4 whereas it is very close to 1 in Table 5 .

\footnotetext{
${ }^{11}$ We utilize Stata's intreg command to estimate the equation and the nlcom command to calculate standard errors.
} 
Importantly, the elicitation mechanism matters for this estimation strategy. $\beta$ is not significantly different from 1 when analyzing the 2PSB data but it is significantly different from 1 when restricting attention to the BDM data. Furthermore, the point estimate of the annual discount rate, $\rho$, for the BDM data (Table 8) ranges from $50.5 \%$ higher when $\alpha=1$ to $26.5 \%$ higher when $\alpha=.259$ compared to the 2PSB auction data (Table 6). As a robustness check, we also run the model on both mechanisms excluding the $\$ 10$ rounds. The same qualitative results hold; there is no present-bias found in the 2PSB auction (Table 7) and significant present-bias found in the BDM mechanism (Table 9). The magnitude of the present-bias in the BDM mechanism decreases in Table 9 when excluding the $\$ 10$ rounds, again suggesting that the small dollar amount may be driving some of the overall present-bias found in the pooled data.

\subsection{Investigating Heterogeneity}

One disadvantage of the previous empirical approaches is that it is difficult to incorporate personal characteristics in any meaningful way. Thus, here we examine an alternative estimation strategy in order to test for heterogeneity in time preferences. We return to equation 5 , add an error term, and have

$$
\frac{c_{t}}{c_{t+k}}=\left(\beta \delta^{k}\right)^{1 / \alpha}+\varepsilon
$$

Recall that $k$ is interval length, which is given in the experimental round and $\alpha$ is the curvature parameter which we are unable to identify. However, once again, we examine results under three assumptions for $\alpha . \beta$ and $\delta$ are the time preference parameters to be estimated via nonlinear least squares. All participants are induced with $c_{t}$ and 2PSB participants reveal $c_{t+k}$ while BDM participants reveal an interval for $c_{t+k}$ in each round of the experimental session. For each BDM participant, denote the lower bound of $c_{t+k}$ as $l b_{t+k}$ and the upper bound of $c_{t+k}$ as $u b_{t+k}$. Then, we form the dependent variable in equation 7 for BDM participants as $\left(c_{t} / l b_{t+k}+c_{t} / u b_{t+k}\right) / 2$. Therefore, the drawback to this empirical approach is that we have some error in how we are measuring the dependent variable for the BDM participants.

We initially examine four specifications. In model $1, \beta$ and $\delta$ are assumed to be the same for everybody. Note that here the interpretation of $\beta$ remains the same in that it is the present-bias parameter. In Model 2, $\beta$ is specified as a function of personal and mechanism characteristics but the monthly discount factor, $\delta$, does not vary across 
individuals. We report results for the reduced mode ${ }^{12}$ where it is specified that present-bias may depend upon the reference dollar amount, employment status, and whether the BDM or 2PSB mechanism is utilized; $\beta=\beta_{0}+\beta_{1}$ referencedollar + $\beta_{2}$ employed $+\beta_{3} B D M$. In model $3, \beta$ does not vary across individuals but $\delta$ is specified as a function of personal and mechanism characteristics. We let $\delta=\delta_{0}+$ $\delta_{1}$ referencedollar $+\delta_{2}$ age $+\delta_{3}$ male $+\delta_{4}$ employed $+\delta_{5}$ income $+\delta_{6} B D M+\delta_{7} O W U$. Finally, in Model 4, we specify both $\beta$ and $\delta$ as functions of personal and mechanism characteristics.

Tables 10, 11, and 12 present results for all four models for three different values of $\alpha .{ }^{13}$ We include rows to reflect average fitted values of $\beta$ and the average fitted annual discount rate, $\widehat{\rho}^{14}$ As in the previous subsection, assumptions on $\alpha$ change only the point estimates of parameters; there is no change to the statistical significance of discounting parameters, personal characteristics, or mechanism characteristics. We first address the present-bias parameter and then the monthly discount factor.

There is statistically significant present-bias when no heterogeneity is assumed in Model 1. The magnitude of the present-bias is similar to that found in the interval regressions in Section 5.2 (Table 3). From Models 2 and 4, we can see that a higher reference dollar amount leads to less present-bias. This is consistent with the other results in this paper and is consistent with a magnitude effect due to either rounding or transaction costs. The only personal characteristic that can significantly explain the extent of present-bias is employment status. We find that employed individuals are associated with being less present-biased. It could be that being employed provides more liquidity, which attenuates the present-bias. Or, it could be that students with less present-biased time preferences are more likely to work because they are more willing to take on the present opportunity cost of working. In Model 3, we see that incorporating heterogeneity into the monthly discount factor results in the presentbias parameter no longer being significantly different from $1 .{ }^{15}$ In this nonlinear least squares analysis, Model 2 suggests that the BDM mechanism produces present-bias relative to the $2 \mathrm{PSB}$ mechanism. This is no longer the case when we allow the monthly

\footnotetext{
${ }^{12} \mathrm{~A}$ model assuming that $\beta$ depends on reference dollar amount, age, gender, employment status, income, experimental mechanism (BDM/2PSB), and university and assuming that $\delta$ is a constant was initially run. In the $\beta$ specification, only coefficients on reference dollar amount, employment status, and experimental mechanism were significant. These results are available upon request.

${ }^{13}$ Standard errors are clustered at the subject level for all of these regressions.

${ }^{14} \rho$ is calculated as $\delta^{-12}-1$. The average fitted values of $\beta$ and $\rho$ are of course the same as the constant for models with no heterogeneity in the corresponding parameter. For the models with heterogeneity, we predict the values of $\beta$ and $\rho$ for each observation and report the average of these predicted values.

${ }^{15} \mathrm{~A}$ one sided test of $\beta$ against 1 does find weak evidence that $\beta<1(\mathrm{p}$-value $=0.063)$.
} 
discount factor to depend on the elicitation mechanism in Model 4.

As for the monthly discount factor, Model 3 provides evidence that individuals are more patient when the magnitude of the reward is larger and when they are employed. None of the other observable personal characteristics seem to systematically explain the monthly discount factor. The lower estimated discount factor for BDM participants in Model 3 implies a higher estimated discount rate. The results from Model 3 imply an average estimated annual discount rate of around $140 \%$ for the case of linear utility and $23.5 \%$ for the case of $\alpha=0.259$. Central to the most important finding of this paper, Models 3 and 4 show that individuals are more patient for choices with larger magnitudes in the reference amount.

\subsection{Maximum Likelihood Estimation}

All empirical strategies utilized thus far have their respective disadvantages. Therefore, we next follow the Andersen et al. (2008) approach of directly estimating the discounting parameters of the utility function via maximum likelihood. This maximum likelihood approach has the benefit that we can be explicit about the assumptions of the underlying behavioral noise parameters. Additionally, we can readily incorporate observable heterogeneity, test for present-bias, appropriately model the interval nature of the BDM data, and address the implications of background consumption. Returning to our utility specification and incorporating background consumption, $\omega$, an individual is indifferent between the reference time period monetary reward, $c_{t}$, and the delayed monetary reward, $c_{t+k}$, when

$$
\left(c_{t}+\omega\right)^{\alpha}+\beta \delta^{k} \omega^{\alpha}=\left\{\begin{array}{c}
\omega^{\alpha}+\beta \delta^{k}\left(c_{t+k}+\omega\right)^{\alpha} \text { if } t=0, \text { and } \\
\omega^{\alpha}+\delta^{k}\left(c_{t+k}+\omega\right)^{\alpha} \text { if } t>0
\end{array}\right\}
$$

Denote the lefthand side of equation 8 (the discounted utility of the reference payment option) as $U_{\text {ref }}$ and the righthand side of equation 8 (the discounted utility of the delayed payment option) as $U_{\text {delyed }}$. Next, denote the latent index of the utility differences as

$$
\Delta U=U_{\text {ref }}-U_{\text {delayed }}
$$

Then, in a deterministic world, an individual chooses the reference period reward when $\Delta U>0$, the delayed reward when $\Delta U<0$, and is indifferent when $\Delta U=0$.

The two different elicitation mechanisms produce distinct data that require differ- 
ent analyses. For the BDM data, we do not observe indifferent observations ${ }^{16}$, while for the 2PSB data, we observe only indifferent observations. We first address the BDM data. Here, the researcher needs to make a decision about the error structure. One possibility, originally due to Fechner, popularized by Hey and Orme (1994) in the context of expected utility and utilized by Andersen et al. (2013) and Andersen et al. (2012) in the contexts of discounting and risk aversion is to specify a behavioral error, $\eta$. This places the error at the final point of the choice between the two rewards. ${ }^{17}$ The Fechner error specification replaces 9 with

$$
\Delta U^{\prime}=\frac{U_{\text {ref }}-U_{\text {delayed }}}{\eta},
$$

where $\eta$ is a noise parameter. We link this latent index (10) to observed BDM choices using the cumulative normal distribution, $\Phi($.$) . This link function takes any input and$ transforms it to a number in the $(0,1)$ interval. As $\eta$ gets larger, the choice becomes more random, flattening out the link functions. As $\eta$ gets smaller and approaches 1, the specification collapses to the deterministic model (Andersen et al., 2013). Then, the probability that an individual chooses the reference period reward equals $\Phi\left(\Delta U^{\prime}\right)$ and the probability that an individual chooses the delayed reward equals $1-\Phi\left(\Delta U^{\prime}\right)$. Denote the choices of an individual as $y_{i}$, where $y_{i}=0$ for a choice of the reference period reward, $y_{i}=1$ for a choice of the delayed reward, and $y_{i}=-1$ for an indifferent observation from the BDM. Thus, the log-likelihood function for the BDM data is

$$
\begin{aligned}
\sum_{i=1}^{n} I\left(y_{i}\right. & =0) \ln \Phi\left(\Delta U_{i}^{\prime}\right)+I\left(y_{i}=1\right) \ln \left(1-\Phi\left(\Delta U_{i}^{\prime}\right)\right) \\
+I\left(y_{i}\right. & =-1)\left(\frac{1}{2} \ln \Phi\left(\Delta U_{i}^{\prime}\right)+\frac{1}{2}\left(1-\Phi\left(\Delta U_{i}^{\prime}\right)\right) .\right.
\end{aligned}
$$

Next, we address the 2PSB data. Returning to equation 9 , we have $\Delta U=0$. That is, $U_{\text {ref }}=U_{\text {delayed }}$. Again, we specify a behavioral error term, $\mu$. Note that $\mu \neq \eta$ in general because these two choices are coming from two different elicitation mechanisms. Assuming a normal distribution, the log-likelihood function for the

\footnotetext{
${ }^{16}$ There is one exception to this. We assume that discount rates are never negative (discount factors are never greater than one). Therefore, an individual in the BDM mechanism who chooses a delayed reward equal to the reference reward is assumed to be indifferent between the two rewards (a discount rate of $0 \%$ ).

${ }^{17}$ One could make other assumptions about the error structure. For example, Meyer (2013) places the error at the level of the utility evaluation of one time period. Wilcox (2008) provides an overview of the assortment of error specifications used in these type of discrete choice models.
} 
estimation of the $2 \mathrm{PSB}$ data is

$$
\sum_{i=1}^{n}\left[\ln \phi\left(\Delta U_{i} / \mu\right)-\ln \mu\right.
$$

where $\phi($.$) is the normal density function. We then combine the log-likelihood equa-$ tions together and generate maximum likelihood estimates from the pooled data. ${ }^{18}$ We cluster standard errors at the subject level for all estimates.

It is plausible that the behavioral noise parameters, $\eta$ and $\mu$, could vary according to experimental design characteristics or personal characteristics. To begin, we assume that both noise parameters are functions of reference reward size, age, gender, employment status, income, and university. Only reference reward size and employment status significantly explain the noise parameters in these specifications. ${ }^{19}$ Therefore, for all maximum likelihood specifications, we assume that noise parameters are functions of reference reward size and employment status. We exogenously set background consumption equal to $0^{20}$ and once again examine results for three value of $\alpha$.

Table 13 shows results for $\alpha=1$. In Model 1 , where $\beta$ and $\delta$ are modeled as constants, we fail to reject exponential discounting since $\beta$ is not statistically different from $1 .{ }^{21}$ Furthermore, the point estimate of the present-bias $\beta$ parameter is approximately 0.98 , consistent with the results from the other regression strategies. Model 2 places the heterogeneity in the $\beta$ parameter while Model 3 places the heterogeneity in the $\delta$ parameter. ${ }^{22}$ In Model 2 , we once again see that the present-bias is reduced with higher reference dollar amounts. However, we no longer find evidence that present-bias differs between the two elicitation mechanisms. In Model 3, we again find evidence that the discount factor (rate) increases (decreases) with the size of the reference dollar amount. That is, individuals appear to be relatively more pa-

\footnotetext{
${ }^{18}$ Maximum likelihood estimates from the separate analyses of data from each elicitation mechanism are available upon request. In all cases, we estimate the model using Stata's maximum likelihood capabilities. Harrison and Rutstrom (2008) provide helpful pedagogic notes on estimating maximum likelihood models of utility functions within Stata.

${ }^{19}$ These results are available upon request.

${ }^{20} \mathrm{We}$ set background consumption to 0 for comparability with results from the previous estimation strategies. Note that background consumption does not matter for the case of linear utility $(\alpha=1)$. We show results for different levels of background consumption and $\alpha$ in the appendix.

${ }^{21}$ We find weak evidence to reject the null of the one sided test of $\beta$ against 1 (p-value $\left.=0.065\right)$.

${ }^{22}$ We initially estimated models 2 and 3 with the respective discounting parameters being functions of reference dollar amount, employment status, elicitation mechanism, age, gender, income, and university. Age, gender, income, and university are not significant and respective Wald tests fail to reject their joint equality to 0 . Hence, we proceed with discounting parameters as functions of only reference dollar amount, employment status, and elicitation mechanism.
} 
tient for larger stakes, consistent with the magnitude effect. As with the present-bias parameter, the elicitation mechanism does not appear to affect the monthly discount factor.

Finally, in Model 4, we specify heterogeneity in the present-bias parameter and in the monthly discount factor. ${ }^{23}$ We see the same results with regards to the magnitude of the reference dollar amount; larger dollar amounts lead to less present-bias and higher discount factors. Consistent with the results from the nonlinear least squares estimates, we see evidence throughout Table 13 that employment status is important for explaining present-bias and patience. Moreover, both noise parameters are related to the size of the reference dollar amount and employment status.

Tables 14 and 15 present maximum likelihood results for the utility curvature parameter, $\alpha$, equal to 0.92 and 0.259. On the whole, these maximum likelihood estimates are quite similar to the corresponding results from the first two regression strategies. In general, there are two differences in these ML results compared to the interval and NLLS regression results. The most important difference is that the elicitation mechanism does not play a significant role in explaining present-bias or discount factors in these maximum likelihood estimates. In general, it seems that the explicit treatment of the noise parameters in the maximum likelihood estimation makes a difference. This underscores the importance of modeling behavioral noise when comparing discounting parameters from different elicitation mechanisms. A minor difference between the ML results and the interval and NLLS results is that the statistical significance of the present-bias parameter, $\beta$, differs slightly. The interval and NLLS regressions find that $\beta$ is statistically different from 1 , whereas $\beta$ is not statistically different from 1 at conventional levels in the maximum likelihood results. $^{24}$ However, the corresponding point estimates of $\beta$ are quite similar across the estimation strategies. In all cases, the magnitude of the estimated present-bias is not substantial.

We provide a sense of the scale of the magnitude effect in Table 16. We take the Model 4 maximum likelihood results from Tables 13, 14, and 15 and use the data to predict average values of the present-bias parameter, $\beta$, and the annual discount rate, $\rho$, for reference dollar amounts of $\$ 10$ and $\$ 100$. As seen in Table 16 , there is a substantial magnitude effect in our results. The magnitude of the reference dollar

\footnotetext{
${ }^{23}$ We first estimated Model 4 including an indicator for BDM in the $\beta$ and $\delta$ specifications. Both coefficients are insignificant and we fail to reject the Wald test null of the joint equality to 0 of the two parameters. The results on the remaining parameters are nearly identical to those reported here and are available upon request.

${ }^{24}$ However, there is weak statistical evidence in the ML results that $\beta<1$ from one sided tests.
} 
reward is important for explaining the extent of present-bias for linear utility $(\alpha=1)$. There, an average individual is predicted to have a $\beta$ parameter that is $6.5 \%$ higher for a reference dollar amount of $\$ 100$ compared to a $\$ 10$ reference amount. ${ }^{25}$ However, the magnitude of the reward becomes less important for explaining the extent of present-bias as the curvature of the utility function increases (as $\alpha$ decreases). On the other hand, the magnitude of the reference dollar reward explains a substantial portion of the difference in estimated annual discount rates, $\rho$, no matter what we assume for the curvature of the utility function. An average individual is predicted to have a discount rate ranging from $18.5 \%$ lower $(\alpha=0.259)$ to $31.3 \%$ lower $(\alpha=1)$ for a $\$ 100$ reference amount compared to a $\$ 10$ reference amount.

Several studies have shown that accounting for unobserved heterogeneity in the discount rate can be important (Andersen et al., 2012, 2013, 2014). Furthermore, our initial examination of the distribution of discount rates in Section 5.1 suggests substantial heterogeneity. Thus, as a final robustness check, we estimate a random coefficients specification. Here, we assume that the discount factor, $\delta$, is randomly distributed according to a normal distribution across individuals and discounting tasks. We then estimate the mean and the standard deviation of $\delta$. The first model restricts $\beta$ to be equal to 1 , and hence represents an exponential discounting specification. The second model allows $\beta$ to differ from 1 , but assumes that it is constant throughout the population. Estimating these random coefficients models requires maximum simulated likelihood methods. The intuition of maximum simulated likelihood is as follows. First, we utilize Halton Draws to draw from a standard normal distribution in an efficient manner (Train, 2003). We draw $R$ random deviates for each discounting task faced by an individual. For each of the $R$ random draws, we evaluate the likelihood as given by equations 11 and 12, where we substitute the "random" $\delta$, which is comprised of a mean plus a standard deviation multiplied by the random Halton draw. Then, we average the likelihoods from the $R$ random draws together to simulate the log likelihood equation. We follow the numerical methods developed for Stata by Cappellari and Jenkins (2006), which are utilized in Andersen et al. (2008) and illustrated in Harrison and Rutstrom (2008).

Table 17 presents results for the two random coefficients models, for three assumptions on the utility curvature parameter, $\alpha$. As expected, there is significant

\footnotetext{
${ }^{25}$ We note also that this pattern could not be explained by subject uncertainty in the receipt of a future reward relative to an immediate reward. For example, if individuals were $10 \%$ less certain that they would receive a future reward relative to an immediate reward, this would produce an observed present-bias in smaller dollar rewards and in larger dollar rewards. Subject uncertainty in future rewards has been proposed as one explanation for findings of present-bias (Halevy, 2008).
} 
heterogeneity in the discount factor. Estimates for the mean monthly discount factor, $\delta$, are in line with the corresponding results from the other estimation strategies. Here, we find a present-bias parameter, $\beta$, that is statistically different from 1 . However, even for the linear utility case, the scale of the present-bias is not substantial with a point estimate on $\beta$ of approximately 0.96. Furthermore, the extent of the present-bias declines as we assume more curvature in the utility function. Therefore, we conclude that we do not have strong evidence in favor of present-biased discounting.

The random coefficients results in Table 17 include all observations from all reference dollar magnitudes. To investigate the magnitude effect, we split the sample into 2 subsamples and estimate exponential discount factors (Model 1) under the assumption of linear utility ${ }^{26}$; choices from reference dollar amounts of $\$ 10$ and $\$ 50$ form one subsample and the choices from reference dollar amounts of $\$ 100$ and $\$ 500$ form the other subsample. We estimate a monthly discount factor with a mean of 0.906 and a standard deviation of 0.0477 for the small reference dollar amounts while we estimate a monthly discount factor with a mean of 0.934 and a standard deviation of 0.0398 for the large reference dollar amounts. This is equivalent to mean annual discount rates of $226 \%$ for the small reference amounts and $126 \%$ for the large reference amounts. Thus, the mean annual discount rate is approximately $40 \%$ smaller for the large reference amounts compared to the small reference amounts. Therefore, the magnitude effect persists when addressing unobserved heterogeneity.

\section{Conclusion}

76 subjects participated in experiments with real and substantial monetary rewards. We estimate aggregate discount rates that are considerably higher than typical interest rates in capital markets, but not out of line with other money discounting experiments. More important than the level of the estimated discount rates, however, are the observed patterns in the discount rates. We find robust evidence that discount rates are higher for smaller dollar rewards. The substantial magnitude effects for the annual discount rate persist regardless of the utility curvature assumptions. These findings related to the magnitude of the reward are important because they are consistent with transaction cost or rounding explanations. Researchers try their best to reduce the transaction cost of retrieving a future reward, but it is difficult

\footnotetext{
${ }^{26}$ Results for other values of $\alpha$ follow the same pattern. Complete results from these subsamples are available upon request.
} 
to completely eradicate it. Similarly, it is not clear how a researcher can effectively prevent the tendency of subjects to utilize rounding. An important takeaway message is that discount rates from studies with very small rewards may significantly overstate the rates that individuals would use for decisions with significantly larger stakes.

Contrary to some previous studies, we find little evidence in support of presentbiased discounting. We do find evidence that there is more present-bias for smaller dollar rewards. However, the little present-bias that we find for the small $\$ 10$ stakes (and with an assumption of linear utility) erodes away with larger stakes and/or the assumption of concave utility. Therefore, we add to some recent evidence that calls into question the universality of hyperbolic discounting (Andersen et al., 2014; Halevy, 2015; Meyer, 2013).

Using a random coefficients specification, we find evidence of substantial unobserved heterogeneity in discount rates. Addressing this unobserved heterogeneity does not substantially alter the extent of the estimated present-bias nor the average estimate of the annual discount rate. Furthermore, evidence of a magnitude effect persists in the random coefficients results. In our sample of college students, employment status is the only observable personal characteristic that can explain heterogeneity in discounting parameters.

Previous research suggests that the 2PSB mechanism may be better at eliminating preference anomalies than the BDM mechanism or that individuals may fundamentally misunderstand the BDM mechanism and therefore make mistakes. We build on this literature and, with several estimation strategies, find some evidence that the discount rates are higher from the BDM mechanism (a choice task) than from the 2PSB mechanism (a matching task). This finding of higher rates from a choice task than from a matching task agrees with other studies. However, once adequately addressing the different behavioral noise from the two different elicitation mechanisms, the resulting maximum likelihood estimates do not significantly differ. Thus, our findings underscore that a comparison of inferred discount rates from different elicitation mechanisms without a structural model of the latent preferences can be misleading.

\section{References}

Ahlbrecht, M., Weber, M., Jun 1997. An empirical study on intertemporal decision making under risk. Management Science 43 (6), 813-826.

Andersen, S., Harrison, G. W., Hole, A. R., Lau, M., Rutstrom, E. E., Jul 2012. 
Non-linear mixed logit. Theory and Decision 73 (1), 77-96.

Andersen, S., Harrison, G. W., Lau, M. I., Rutstrom, E. E., 2008. Eliciting risk and time preferences. Econometrica 76 (3), 583-618.

Andersen, S., Harrison, G. W., Lau, M. I., Rutstrom, E. E., Oct 2013. Discounting behaviour and the magnitude effect: Evidence from a field experiment in denmark. Economica 80 (320), 670-697.

Andersen, S., Harrison, G. W., Lau, M. I., Rutstrom, E. E., Oct 2014. Discounting behavior: A reconsideration. European Economic Review 71, 15-33.

Andreoni, J., Sprenger, C., 2012a. Estimating time preferences from convex budgets. American Economic Review 102 (7), 3333-56.

Andreoni, J., Sprenger, C., 2012b. Risk preferences are not time preferences. American Economic Review 102 (7), 3357-76.

Becker, G. M., Degroot, M. H., Marschak, J., 1964. Measuring utility by a singleresponse sequential method. Behavioral Science 9 (3), 226-232.

Benhabib, J., Bisin, A., Schotter, A., Jul 2010. Present-bias, quasi-hyperbolic discounting, and fixed costs. Games and Economic Behavior 69 (2), 205-223.

Braga, J., Starmer, C., 2005. Preference anomalies, preference elicitation and the discovered preference hypothesis. Environmental and Resource Economics 32, 5589.

Cairns, J., van der Pol, M., April 2000. Valuing future private and social benefits: The discounted utility model versus hyperbolic discounting models. Journal of Economic Psychology 21 (2), 191-205.

Cappellari, L., Jenkins, S. P., 2006. Calculation of multivariate normal probabilities by simulation, with applications to maximum simulated likelihood estimation. Stata Journal 6 (2), 156-189.

Cason, T. N., Plott, C. R., 2014. Misconceptions and game form recognition: Challenges to theories of revealed preference and framing. Journal of Political Economy 122 (6), 1235-1270.

Chakraborty, A., Calford, E. M., Fenig, G., Halevy, Y., 2015. External and internal consistency of choices made in convex time budgets. 
Coller, M., Williams, M. B., December 1999. Eliciting individual discount rates. Experimental Economics 2 (2), 107-127.

Cronbach, L., 09/01 1951. Coefficient alpha and the internal structure of tests. Psychometrika 16 (3), 297-334.

Frederick, S., Loewenstein, G., O’Donoghue, T., June 2002. Time discounting and time preference: A critical review. Journal of Economic Literature 40 (2), 351-401.

Halevy, Y., Jun 2008. Strotz meets allais: Diminishing impatience and the certainty effect. American Economic Review 98 (3), 1145-1162.

Halevy, Y., 2015. Time consistency: Stationarity and time invariance. Econometrica 83 (1), 335-352.

Hardisty, D. J., Thompson, K. F., Krantz, D. H., Weber, E. U., 2013. How to measure time preferences: An experimental comparison of three methods. Judgment and Decision Making 8 (3), 236-249.

Harrison, G. W., Lau, M. I., Williams, M. B., December 2002. Estimating individual discount rates in Denmark: A field experiment. American Economic Review 92 (5), 1606-1617.

Harrison, G. W., Rutstrom, E., 2008. Risk Aversion in the Laboratory. Vol. 12 of Risk Aversion in Experiments. JAI, Bingley, pp. 41-196.

Harvey, C. M., Sep. 1986. Value functions for infinite-period planning. Management Science 32 (9), 1123-1139.

Herrnstein, R., 1981. Self-control as response strength. In: Bradshaw, C. M., Szabadi, E., Lowe, C. F. (Eds.), Quantification of Steady-State Operant Behavior. Elsevier/North-Holland, New York, pp. 3-20.

Hey, J. D., Orme, C., Nov 1994. Investigating generalizations of expected utility theory using experimental data. Econometrica 62 (6), 1291-1326.

Kahneman, D., Knetsch, J. L., Thaler, R. H., 1990. Experimental tests of the endowment effect and the coase theorem. Journal of Political Economy 98 (6), 1325-48.

Keller, L. R., Strazzera, E., March 2002. Examining predictive accuracy among discounting models. Journal of Risk and Uncertainty 24 (2), 143-160. 
Kirby, K. N., Marakovic, N. N., October 1995. Modeling myopic decisions: Evidence for hyperbolic delay-discounting within subjects and amounts. Organizational Behavior and Human Decision Processes, 64 (1), 22-30.

Laibson, D., May 1997. Golden eggs and hyperbolic discounting. Quarterly Journal of Economics 112 (2), 443-477.

Manzini, P., Mariotti, M., Mittone, L., 2008. The elicitation of time preferences. Tech. rep., Cognitive and Experimental Economics Laboratory, Department of Economics, University of Trento, Italia.

Mazur, J. E., 1987. An adjustment procedure for studying delayed reinforcement. In: Commons, M. L., Mazur, J. E., Nevin, J. A., Rachlin, H. (Eds.), Quantitative analysis of behaviour: The effect of delay and intervening events on reinforcement value. Erlbaum, Hillsdale, NJ.

Meyer, A., 04 2013. Estimating discount factors for public and private goods and testing competing discounting hypotheses. Journal of Risk and Uncertainty 46 (2), $133-173$.

Noussair, C., Robin, S., Ruffieux, B., 2004. Revealing consumers' willingness-to-pay: A comparison of the bdm mechanism and the vickrey auction. Journal of Economic Psychology 25 (6), $725-741$.

Phelps, E. S., Pollak, R. A., Apr. 1968. On second-best national saving and gameequilibrium growth. The Review of Economic Studies 35 (2), 185-199.

Read, D., Roelofsma, P. H. M. P., 7 2003. Subadditive versus hyperbolic discounting: A comparison of choice and matching. Organizational behavior and human decision processes 91 (2), 140-153.

Samuelson, P. A., Feb. 1937. A note on measurement of utility. The Review of Economic Studies 4 (2), 155-161.

Shogren, J. F., Cho, S., Koo, C., List, J., Park, C., Polo, P., Wilhelmi, R., 2001. Auction mechanisms and the measurement of wtp and wta. Resource and Energy Economics 23 (2), 97 - 109.

Shogren, J. F., Shin, S. Y., Hayes, D. J., Kliebenstein, J. B., 1994. Resolving differences in willingness to pay and willingness to accept. The American Economic Review, 255-270. 
Slonim, R., Carlson, J., Bettinger, E., 12 2007. Possession and discounting behavior. Economics Letters, 97 (3), 215-221.

Train, K. E., 2003. Discrete Choice Methods with Simulation. Cambridge University Press, New York, NY.

Vickrey, W., 1961. Counterspeculation, auctions, and competitive sealed tenders. The Journal of Finance 16 (1), 8-37.

Wilcox, N. T., 2008. Stochastic Models for Binary Discrete Choice Under Risk: A Critical Primer and Econometric Comparison. Vol. 12 of Risk Aversion in Experiments. JAI, Bingley.

Table 1: Experimental Sessions

\begin{tabular}{cccccc}
\hline \hline Session & \# Subjects & \# Rounds & Auction Type & Ref. Dollar & Location \\
\hline 1 & 7 & 6 & BDM & 10,100 & OWU \\
2 & 8 & 4 & 2 PSB & 100 & CU \\
3 & 8 & 6 & BDM & 10,500 & CU \\
4 & 8 & 5 & BDM & 100 & OWU \\
5 & 8 & 5 & BDM & 100 & OWU \\
6 & 8 & 5 & $2 P S B$ & 50,100 & OWU \\
7 & 7 & 8 & $2 P S B$ & 10,100 & OWU \\
8 & 6 & 8 & $2 P S B$ & 10,100 & OWU \\
9 & 6 & 8 & $2 P S B$ & 10,100 & OWU \\
10 & 3 & 4 & BDM & 100 & CU \\
11 & 7 & 6 & $2 P S B$ & 50,100 & OWU \\
\hline \hline
\end{tabular}


Table 2: Nonparametric Descriptive Rates

\begin{tabular}{cccccccc}
\hline \hline \multicolumn{2}{l}{ Distribution of $\rho$, Including all Observations } & & & & \\
Percentile & Full Sample & BDM & 2PSB & $\$ 10$ & $\$ 50$ & $\$ 100$ & $\$ 500$ \\
\hline 25 & 0.134 & 0.371 & 0.073 & 0.398 & 0.518 & 0.126 & 0.09 \\
50 & 0.796 & 0.977 & 0.796 & 2.84 & 2.14 & 0.629 & 0.31 \\
75 & 3.54 & 5.88 & 2.84 & 13.9 & 11.5 & 2.13 & 0.90 \\
95 & 119 & 701 & 35.6 & 15167 & 3060 & 23.4 & 2.90 \\
98 & 3949 & 15167 & 1555 & 1994809 & 4095 & 110 & 3.61 \\
\hline Mean & 36172 & 88623 & 284.46 & 172237 & 226.68 & 27.33 & 0.722 \\
\hline \hline
\end{tabular}

Distribution of $\rho$, Excluding Top $5 \%$ of Obervations

\begin{tabular}{cccccccc} 
Percentile & Full Sample & BDM & 2 PSB & $\$ 10$ & $\$ 50$ & $\$ 100$ & $\$ 500$ \\
\hline 25 & 0.127 & 0.261 & 0.063 & 0.398 & 0.198 & 0.124 & 0.09 \\
50 & 0.772 & 0.793 & 0.760 & 2.14 & 2.14 & 0.563 & 0.31 \\
75 & 2.84 & 3.32 & 2.14 & 6.58 & 4.38 & 1.99 & 0.90 \\
95 & 18.8 & 29.6 & 13.8 & 55.7 & 29.8 & 14.8 & 2.90 \\
98 & 35.6 & 107.1 & 31.5 & 107.1 & 33.0 & 30.4 & 3.61 \\
\hline Mean & 4.276 & 6.179 & 3.012 & 8.454 & 4.279 & 3.478 & 0.722 \\
\hline \hline
\end{tabular}

Table 3: Discounting Estimates, Pooled Data

\begin{tabular}{lccc}
\hline \hline & $(1)$ & $(2)$ & $(3)$ \\
& $\alpha=1$ & $\alpha=.92$ & $\alpha=.259$ \\
\hline$\hat{\rho}$ & $1.302^{* * *}$ & $1.153^{* * *}$ & $0.241^{* * *}$ \\
& $(0.218)$ & $(0.188)$ & $(0.0305)$ \\
$\hat{\beta}$ & & & \\
& $0.966^{*}$ & $0.969^{*}$ & $0.991^{*}$ \\
& $(0.0183)$ & $(0.0169)$ & $(0.00486)$ \\
\hline \hline
\end{tabular}

Standard errors in parentheses are clustered at the subject level

${ }^{*} p<0.10,{ }^{* *} p<0.05,{ }^{* * *} p<0.01$

$\rho$ tested against $0, \beta$ tested against 1 
Table 4: Discounting Estimates, 10 Dollar Only

\begin{tabular}{lccc}
\hline \hline & $(1)$ & $(2)$ & $(3)$ \\
& $\alpha=1$ & $\alpha=.92$ & $\alpha=.259$ \\
\hline$\hat{\rho}$ & $1.800^{* *}$ & $1.579^{* * *}$ & $0.306^{* * *}$ \\
& $(0.712)$ & $(0.603)$ & $(0.0860)$ \\
$\hat{\beta}$ & & & \\
& 0.892 & 0.900 & 0.971 \\
& $(0.0897)$ & $(0.0833)$ & $(0.0253)$ \\
\hline \hline
\end{tabular}

Standard errors in parentheses are clustered at the subject level

${ }^{*} p<0.10,{ }^{* *} p<0.05,{ }^{* * *} p<0.01$

$\rho$ tested against $0, \beta$ tested against 1

Table 5: Discounting Estimates, 50, 100, 500 Dollar Levels

\begin{tabular}{lccc}
\hline \hline & $(1)$ & $(2)$ & $(3)$ \\
& $\alpha=1$ & $\alpha=.92$ & $\alpha=.259$ \\
\hline$\hat{\rho}$ & $1.166^{* * *}$ & $1.036^{* * *}$ & $0.222^{* * *}$ \\
& $(0.228)$ & $(0.197)$ & $(0.0333)$ \\
$\hat{\beta}$ & & & \\
& 1.007 & 1.006 & 1.002 \\
\hline Observations & 354 & 354 & 354 \\
\hline \hline
\end{tabular}

Standard errors in parentheses are clustered at the subject level

${ }^{*} p<0.10,{ }^{* *} p<0.05,{ }^{* * *} p<0.01$

$\rho$ tested against $0, \beta$ tested against 1

Table 6: Discounting Estimates, 2PSB Only

\begin{tabular}{lccc}
\hline \hline & $(1)$ & $(2)$ & $(3)$ \\
& $\alpha=1$ & $\alpha=.92$ & $\alpha=.259$ \\
\hline$\hat{\rho}$ & $1.145^{* * *}$ & $1.018^{* * *}$ & $0.219^{* * *}$ \\
& $(0.232)$ & $(0.201)$ & $(0.0342)$ \\
$\hat{\beta}$ & 0.992 & 0.993 & 0.998 \\
& $(0.0193)$ & $(0.0178)$ & $(0.00503)$ \\
\hline Observations & 266 & 266 & 266 \\
\hline
\end{tabular}

Standard errors in parentheses are clustered at the subject level

${ }^{*} p<0.10,{ }^{* *} p<0.05,{ }^{* * *} p<0.01$

$\rho$ tested against $0, \beta$ tested against 1 
Table 7: Discounting Estimates, 2PSB Excluding 10 Dollar

\begin{tabular}{lccc}
\hline \hline & $(1)$ & $(2)$ & $(3)$ \\
& $\alpha=1$ & $\alpha=.92$ & $\alpha=.259$ \\
\hline$\hat{\rho}$ & $0.894^{* * *}$ & $0.800^{* * *}$ & $0.180^{* * *}$ \\
& $(0.210)$ & $(0.183)$ & $(0.0338)$ \\
$\hat{\beta}$ & & & \\
& 1.010 & 1.009 & 1.003 \\
\hline Observations & $20.0171)$ & $(0.0157)$ & $(0.00440)$ \\
\hline \hline
\end{tabular}

Standard errors in parentheses are clustered at the subject level

${ }^{*} p<0.10,{ }^{* *} p<0.05,{ }^{* * *} p<0.01$

$\rho$ tested against $0, \beta$ tested against 1

Table 8: Discounting Estimates, BDM Only

\begin{tabular}{lccc}
\hline \hline & $(1)$ & $(2)$ & $(3)$ \\
& $\alpha=1$ & $\alpha=.92$ & $\alpha=.259$ \\
\hline$\hat{\rho}$ & $1.723^{* * *}$ & $1.513^{* * *}$ & $0.296^{* * *}$ \\
& $(0.531)$ & $(0.451)$ & $(0.0655)$ \\
$\hat{\beta}$ & & & \\
& $0.913^{* *}$ & $0.919^{* *}$ & $0.977^{* *}$ \\
\hline Observations & $(0.0405)$ & $(0.0376)$ & $(0.0112)$ \\
\hline \hline
\end{tabular}

Standard errors in parentheses are clustered at the subject level

${ }^{*} p<0.10,{ }^{* *} p<0.05,{ }^{* * *} p<0.01$

$\rho$ tested against $0, \beta$ tested against 1

Table 9: Discounting Estimates, BDM Excluding 10 Dollar

\begin{tabular}{lccc}
\hline \hline & $(1)$ & $(2)$ & $(3)$ \\
& $\alpha=1$ & $\alpha=.92$ & $\alpha=.259$ \\
\hline$\hat{\rho}$ & $1.569^{* * *}$ & $1.382^{* * *}$ & $0.277^{* * *}$ \\
& $(0.481)$ & $(0.410)$ & $(0.0619)$ \\
$\hat{\beta}$ & & & \\
& $0.976^{* *}$ & $0.978^{* *}$ & $0.994^{* *}$ \\
\hline Observations & $10.0117)$ & $(0.0108)$ & $(0.00309)$ \\
\hline \hline
\end{tabular}

Standard errors in parentheses are clustered at the subject level

${ }^{*} p<0.10,{ }^{* *} p<0.05,{ }^{* * *} p<0.01$

$\rho$ tested against $0, \beta$ tested against 1 
Table 10: Nonlinear Least Squares Estimates, $\alpha=1$

\begin{tabular}{|c|c|c|c|c|}
\hline & $\begin{array}{c}1) \\
\text { Model } 1\end{array}$ & $\begin{array}{c}2) \\
\text { Model } 2\end{array}$ & $\begin{array}{c}(3) \\
\text { Model } 3\end{array}$ & $\begin{array}{c}4) \\
\text { Model } 4\end{array}$ \\
\hline \multicolumn{5}{|l|}{$\beta$ Estimation } \\
\hline Constant & $\begin{array}{l}0.973^{* *} \\
(0.0118)\end{array}$ & $\begin{array}{l}0.917^{* * *} \\
(0.0299)\end{array}$ & $\begin{array}{c}0.984 \\
(0.0106)\end{array}$ & $\begin{array}{c}0.970 \\
(0.0251)\end{array}$ \\
\hline Reference Dollar & & $\begin{array}{c}0.000473^{* * *} \\
(0.000150)\end{array}$ & & $\begin{array}{l}0.000227^{*} \\
(0.000121)\end{array}$ \\
\hline Employed & & $\begin{array}{l}0.101^{* * *} \\
(0.0358)\end{array}$ & & $\begin{array}{c}0.0113 \\
(0.0213)\end{array}$ \\
\hline BDM & & $\begin{array}{c}-0.0926^{* *} \\
(0.0464)\end{array}$ & & $\begin{array}{l}-0.0389 \\
(0.0268)\end{array}$ \\
\hline Average $\hat{\beta}$ & 0.973 & 0.981 & 0.984 & 0.984 \\
\hline \multicolumn{5}{|l|}{$\delta$ Estimation } \\
\hline Constant & $\begin{array}{c}0.941^{* * *} \\
(0.00641)\end{array}$ & $\begin{array}{c}0.940^{* * *} \\
(0.00670)\end{array}$ & $\begin{array}{c}0.965 \\
(0.117)\end{array}$ & $\begin{array}{c}0.970 \\
(0.119)\end{array}$ \\
\hline Reference Dollar & & & $\begin{array}{l}0.000164^{* * *} \\
(0.0000475)\end{array}$ & $\begin{array}{l}0.000144^{* * *} \\
(0.0000469)\end{array}$ \\
\hline Age & & & $\begin{array}{c}-0.00210 \\
(0.00542)\end{array}$ & $\begin{array}{l}-0.00228 \\
(0.00548)\end{array}$ \\
\hline Male & & & $\begin{array}{c}-0.00420 \\
(0.0115)\end{array}$ & $\begin{array}{c}-0.00413 \\
(0.0115)\end{array}$ \\
\hline Employed & & & $\begin{array}{c}0.0383^{* * *} \\
(0.0122)\end{array}$ & $\begin{array}{c}0.0366^{* * *} \\
(0.0121)\end{array}$ \\
\hline Income & & & $\begin{array}{c}0.000000257 \\
(0.000000690)\end{array}$ & $\begin{array}{c}0.000000278 \\
(0.000000691)\end{array}$ \\
\hline BDM & & & $\begin{array}{c}-0.0341^{* *} \\
(0.0171)\end{array}$ & $\begin{array}{l}-0.0282^{*} \\
(0.0164)\end{array}$ \\
\hline OWU & & & $\begin{array}{l}-0.0110 \\
(0.0184)\end{array}$ & $\begin{array}{l}-0.0115 \\
(0.0184)\end{array}$ \\
\hline Average $\hat{\rho}$ & 1.067 & 1.089 & 1.395 & 1.337 \\
\hline Observations & 448 & 448 & 448 & 448 \\
\hline Log Likelihood & 129.0 & 144.1 & 167.5 & 169.1 \\
\hline R Squared & 0.955 & 0.958 & 0.962 & 0.962 \\
\hline Subjects & 76 & 76 & 76 & 76 \\
\hline
\end{tabular}

Standard errors in parentheses are clustered at the subject level.

Constants for $\beta$ and $\delta$ are tested against 1 . All others are tested against 0 .

$\delta$ is the monthly discount factor. $\rho$ is the annual discount rate.

${ }^{*} p<0.10,{ }^{* *} p<0.05,{ }^{* * *} p<0.01$ 
Table 11: Nonlinear Least Squares Estimates, $\alpha=0.92$

\begin{tabular}{|c|c|c|c|c|}
\hline & $\begin{array}{c}(1) \\
\text { Model } 1\end{array}$ & $\begin{array}{c}(2) \\
\text { Model } 2\end{array}$ & $\begin{array}{c}(3) \\
\text { Model } 3\end{array}$ & $\begin{array}{c}(4) \\
\text { Model } 4\end{array}$ \\
\hline \multicolumn{5}{|l|}{$\beta$ Estimation } \\
\hline Constant & $\begin{array}{c}0.975^{* *} \\
(0.0109)\end{array}$ & $\begin{array}{l}0.924^{* * *} \\
(0.0276)\end{array}$ & $\begin{array}{c}0.985 \\
(0.00980)\end{array}$ & $\begin{array}{c}0.972 \\
(0.0230)\end{array}$ \\
\hline Reference Dollar & & $\begin{array}{c}0.000433^{* * *} \\
(0.000137)\end{array}$ & & $\begin{array}{l}0.000208^{*} \\
(0.000111)\end{array}$ \\
\hline Employed & & $\begin{array}{c}0.0934^{* * *} \\
(0.0330)\end{array}$ & & $\begin{array}{c}0.0104 \\
(0.0196)\end{array}$ \\
\hline $\mathrm{BDM}$ & & $\begin{array}{c}-0.0856^{* *} \\
(0.0429)\end{array}$ & & $\begin{array}{l}-0.0359 \\
(0.0248)\end{array}$ \\
\hline Average $\hat{\beta}$ & 0.975 & 0.982 & 0.985 & 0.985 \\
\hline \multicolumn{5}{|l|}{$\delta$ Estimation } \\
\hline Constant & $\begin{array}{c}0.946^{* * *} \\
(0.00592)\end{array}$ & $\begin{array}{c}0.945^{* * *} \\
(0.00619)\end{array}$ & $\begin{array}{c}0.968 \\
(0.109)\end{array}$ & $\begin{array}{c}0.973 \\
(0.110)\end{array}$ \\
\hline Reference Dollar & & & $\begin{array}{l}0.000151^{* * *} \\
(0.0000439)\end{array}$ & $\begin{array}{l}0.000133^{\text {*** }} \\
(0.0000434)\end{array}$ \\
\hline Age & & & $\begin{array}{l}-0.00194 \\
(0.00501)\end{array}$ & $\begin{array}{c}-0.00211 \\
(0.00506)\end{array}$ \\
\hline Male & & & $\begin{array}{c}-0.00388 \\
(0.0106)\end{array}$ & $\begin{array}{l}-0.00381 \\
(0.0106)\end{array}$ \\
\hline Employed & & & $\begin{array}{c}0.0354^{* * *} \\
(0.0113)\end{array}$ & $\begin{array}{c}0.0338^{* * *} \\
(0.0112)\end{array}$ \\
\hline Income & & & $\begin{array}{c}0.000000237 \\
(0.000000635)\end{array}$ & $\begin{array}{c}0.000000256 \\
(0.000000636)\end{array}$ \\
\hline $\mathrm{BDM}$ & & & $\begin{array}{c}-0.0315^{* *} \\
(0.0158)\end{array}$ & $\begin{array}{l}-0.0261^{*} \\
(0.0152)\end{array}$ \\
\hline OWU & & & $\begin{array}{l}-0.0103 \\
(0.0170)\end{array}$ & $\begin{array}{l}-0.0106 \\
(0.0170)\end{array}$ \\
\hline Average $\hat{\rho}$ & 0.951 & 0.969 & 1.220 & 1.172 \\
\hline Observations & 448 & 448 & 448 & 448 \\
\hline Log Likelihood & 129.0 & 144.0 & 167.5 & 169.0 \\
\hline R Squared & 0.955 & 0.958 & 0.962 & 0.962 \\
\hline Subjects & 76 & 76 & 76 & 76 \\
\hline
\end{tabular}

Standard errors in parentheses are clustered at the subject level.

Constants for $\beta$ and $\delta$ are tested against 1. All others are tested against 0 .

$\delta$ is the monthly discount factor. $\rho$ is the annual discount rate.

${ }^{*} p<0.10,{ }^{* *} p<0.05,{ }^{* * *} p<0.01$ 
Table 12: Nonlinear Least Squares Estimates, $\alpha=.259$

\begin{tabular}{|c|c|c|c|c|}
\hline & $\begin{array}{c}(1) \\
\text { Model } 1\end{array}$ & $\begin{array}{c}(2) \\
\text { Model } 2\end{array}$ & $\begin{array}{c}(3) \\
\text { Model } 3\end{array}$ & $\begin{array}{c}(4) \\
\text { Model } 4\end{array}$ \\
\hline \multicolumn{5}{|l|}{$\beta$ Estimation } \\
\hline Constant & $\begin{array}{c}0.993^{* *} \\
(0.00312)\end{array}$ & $\begin{array}{c}0.979^{* * *} \\
(0.00790)\end{array}$ & $\begin{array}{c}0.996 \\
(0.00281)\end{array}$ & $\begin{array}{c}0.992 \\
(0.00648)\end{array}$ \\
\hline Reference Dollar & & $\begin{array}{l}0.000118^{* * *} \\
(0.0000368)\end{array}$ & & $\begin{array}{c}0.0000578 * \\
(0.0000305)\end{array}$ \\
\hline Employed & & $\begin{array}{l}0.0264^{* * *} \\
(0.00940)\end{array}$ & & $\begin{array}{c}0.00291 \\
(0.00555)\end{array}$ \\
\hline $\mathrm{BDM}$ & & $\begin{array}{c}-0.0249^{* *} \\
(0.0124)\end{array}$ & & $\begin{array}{c}-0.0104 \\
(0.00718)\end{array}$ \\
\hline Average $\hat{\beta}$ & 0.993 & 0.994 & 0.996 & 0.996 \\
\hline$\delta$ Estimation & & & & \\
\hline Constant & $\begin{array}{c}0.984^{* * *} \\
(0.00173)\end{array}$ & $\begin{array}{c}0.984^{* * *} \\
(0.00181)\end{array}$ & $\begin{array}{c}0.991 \\
(0.0316)\end{array}$ & $\begin{array}{c}0.993 \\
(0.0320)\end{array}$ \\
\hline Reference Dollar & & & $\begin{array}{c}0.0000434^{* * *} \\
(0.0000129)\end{array}$ & $\begin{array}{c}0.0000381^{* * *} \\
(0.0000128)\end{array}$ \\
\hline Age & & & $\begin{array}{r}-0.000587 \\
(0.00146)\end{array}$ & $\begin{array}{r}-0.000632 \\
(0.00148)\end{array}$ \\
\hline Male & & & $\begin{array}{l}-0.00113 \\
(0.00309)\end{array}$ & $\begin{array}{l}-0.00111 \\
(0.00307)\end{array}$ \\
\hline Employed & & & $\begin{array}{l}0.0103^{* * *} \\
(0.00330)\end{array}$ & $\begin{array}{c}0.00988^{* * *} \\
(0.00328)\end{array}$ \\
\hline Income & & & $\begin{array}{c}6.89 \mathrm{e}-08 \\
(0.000000181)\end{array}$ & $\begin{array}{c}7.36 \mathrm{e}-08 \\
(0.000000181)\end{array}$ \\
\hline $\mathrm{BDM}$ & & & $\begin{array}{c}-0.00927^{*} \\
(0.00469)\end{array}$ & $\begin{array}{c}-0.00765^{*} \\
(0.00450)\end{array}$ \\
\hline OWU & & & $\begin{array}{l}-0.00312 \\
(0.00493)\end{array}$ & $\begin{array}{l}-0.00319 \\
(0.00492)\end{array}$ \\
\hline Average $\hat{\rho}$ & 0.207 & 0.210 & 0.235 & 0.230 \\
\hline Observations & 448 & 448 & 448 & 448 \\
\hline Log Likelihood & 129.0 & 143.8 & 167.2 & 168.8 \\
\hline R Squared & 0.955 & 0.958 & 0.962 & 0.962 \\
\hline Subjects & 76 & 76 & 76 & 76 \\
\hline
\end{tabular}

Standard errors in parentheses are clustered at the subject level.

Constants for $\beta$ and $\delta$ are tested against 1 . All others are tested against 0 .

$\delta$ is the monthly discount factor. $\rho$ is the annual discount rate.

${ }^{*} p<0.10,{ }^{* *} p<0.05,{ }^{* * *} p<0.01$ 
Table 13: Maximum Likelihood Estimates, $\alpha=1$

\begin{tabular}{|c|c|c|c|c|}
\hline & $\begin{array}{c}(1) \\
\text { Model } 1\end{array}$ & $\begin{array}{c}(2) \\
\text { Model } 2\end{array}$ & $\begin{array}{c}(3) \\
\text { Model } 3\end{array}$ & $\begin{array}{c}(4) \\
\text { Model } 4\end{array}$ \\
\hline \multicolumn{5}{|l|}{$\beta$ Estimation } \\
\hline Constant & $\begin{array}{c}0.978 \\
(0.0147)\end{array}$ & $\begin{array}{l}0.754^{* * *} \\
(0.0691)\end{array}$ & $\begin{array}{c}0.994 \\
(0.0141)\end{array}$ & $\begin{array}{l}0.902^{* * *} \\
(0.0322)\end{array}$ \\
\hline Reference Dollar & & $\begin{array}{c}0.000865^{* * *} \\
(0.000251)\end{array}$ & & $\begin{array}{c}0.000594^{* * *} \\
(0.000212)\end{array}$ \\
\hline Employed & & $\begin{array}{c}0.138^{* *} \\
(0.0688)\end{array}$ & & $\begin{array}{c}0.0425 \\
(0.0340)\end{array}$ \\
\hline BDM & & $\begin{array}{c}0.0403 \\
(0.0525)\end{array}$ & & \\
\hline Average $\hat{\beta}$ & 0.978 & 0.980 & 0.994 & 1.008 \\
\hline \multicolumn{5}{|l|}{$\delta$ Estimation } \\
\hline Constant & $\begin{array}{l}0.934^{* * *} \\
(0.0105)\end{array}$ & $\begin{array}{c}0.940^{* * *} \\
(0.00982)\end{array}$ & $\begin{array}{l}0.889^{* * *} \\
(0.0150)\end{array}$ & $\begin{array}{l}0.887^{* * *} \\
(0.0179)\end{array}$ \\
\hline Reference Dollar & & & $\begin{array}{l}0.000132^{* * *} \\
(0.0000378)\end{array}$ & $\begin{array}{l}0.000161^{* * *} \\
(0.0000404)\end{array}$ \\
\hline Employed & & & $\begin{array}{c}0.0355^{* * *} \\
(0.0137)\end{array}$ & $\begin{array}{l}0.0371^{* *} \\
(0.0163)\end{array}$ \\
\hline BDM & & & $\begin{array}{l}0.00369 \\
(0.0174)\end{array}$ & \\
\hline Average $\hat{\rho}$ & 1.257 & 1.090 & 1.637 & 1.691 \\
\hline \multicolumn{5}{|l|}{$\eta$ Estimation } \\
\hline Constant & $\begin{array}{c}9.328 \\
(5.932)\end{array}$ & $\begin{array}{l}4.978^{*} \\
(2.913)\end{array}$ & $\begin{array}{l}18.75^{* *} \\
(8.991)\end{array}$ & $\begin{array}{l}4.417^{*} \\
(2.595)\end{array}$ \\
\hline Reference Dollar & $\begin{array}{l}0.251^{* * *} \\
(0.0637)\end{array}$ & $\begin{array}{l}0.281^{* * *} \\
(0.0689)\end{array}$ & $\begin{array}{c}0.0644 \\
(0.0658)\end{array}$ & $\begin{array}{l}0.257^{* * *} \\
(0.0667)\end{array}$ \\
\hline Employed & $\begin{array}{l}-10.25^{*} \\
(5.743)\end{array}$ & $\begin{array}{c}-6.234^{* *} \\
(2.720)\end{array}$ & $\begin{array}{c}1.770 \\
(10.07)\end{array}$ & $\begin{array}{c}-5.454^{* *} \\
(2.375)\end{array}$ \\
\hline \multicolumn{5}{|l|}{$\mu$ Estimation } \\
\hline Constant & $\begin{array}{l}5.735^{* *} \\
(2.278)\end{array}$ & $\begin{array}{l}3.978^{* *} \\
(1.675)\end{array}$ & $\begin{array}{l}3.746^{* *} \\
(1.585)\end{array}$ & $\begin{array}{l}3.205^{* *} \\
(1.334)\end{array}$ \\
\hline Reference Dollar & $\begin{array}{l}0.175^{* * *} \\
(0.0231)\end{array}$ & $\begin{array}{l}0.179^{* * *} \\
(0.0251)\end{array}$ & $\begin{array}{l}0.172^{* * *} \\
(0.0258)\end{array}$ & $\begin{array}{l}0.174^{* * *} \\
(0.0224)\end{array}$ \\
\hline Employed & $\begin{array}{c}-5.297^{* *} \\
(2.133)\end{array}$ & $\begin{array}{c}-3.703^{* *} \\
(1.526)\end{array}$ & $\begin{array}{c}-3.362^{* *} \\
(1.396)\end{array}$ & $\begin{array}{c}-2.907^{* *} \\
(1.204)\end{array}$ \\
\hline Observations & 5180 & 5180 & 5180 & 5180 \\
\hline Log Likelihood & -3195.3 & -3139.8 & -3081.6 & -3023.5 \\
\hline Subjects & 76 & 76 & 76 & 76 \\
\hline
\end{tabular}

Standard errors in parentheses are clustered at the subject level.

Constants for $\beta$ and $\delta$ are tested against 1 . All others are tested against 0 .

$\delta$ is the monthly discount factor. $\rho$ is the annual discount rate.

${ }^{*} p<0.10,{ }^{* *} p<0.05,{ }^{* * *} p<0.01$ 
Table 14: Maximum Likelihood Estimates, $\alpha=0.92$

\begin{tabular}{|c|c|c|c|c|}
\hline & $\begin{array}{c}\text { (1) } \\
\text { Model } 1\end{array}$ & $\begin{array}{c}(2) \\
\text { Model } 2\end{array}$ & $\begin{array}{c}(3) \\
\text { Model } 3\end{array}$ & $\begin{array}{c}(4) \\
\text { Model } 4\end{array}$ \\
\hline \multicolumn{5}{|l|}{$\beta$ Estimation } \\
\hline Constant & $\begin{array}{c}0.982 \\
(0.0134)\end{array}$ & $\begin{array}{l}0.776^{* * *} \\
(0.0628)\end{array}$ & $\begin{array}{c}0.999 \\
(0.012)\end{array}$ & $\begin{array}{c}0.957^{*} \\
(0.0250)\end{array}$ \\
\hline Reference Dollar & & $\begin{array}{c}0.000875^{* * *} \\
(0.000255)\end{array}$ & & $\begin{array}{l}0.0000797 \\
(0.000103)\end{array}$ \\
\hline Employed & & $\begin{array}{c}0.129^{* *} \\
(0.0633)\end{array}$ & & $\begin{array}{c}0.0442^{*} \\
(0.0266)\end{array}$ \\
\hline BDM & & $\begin{array}{c}0.0289 \\
(0.0479)\end{array}$ & & \\
\hline Average $\hat{\beta}$ & 0.982 & 0.989 & 0.999 & 0.988 \\
\hline \multicolumn{5}{|l|}{$\delta$ Estimation } \\
\hline Constant & $\begin{array}{c}0.939^{* * *} \\
(0.00975)\end{array}$ & $\begin{array}{c}0.944^{* * *} \\
(0.00908)\end{array}$ & $\begin{array}{l}0.892^{* * *} \\
(0.0158)\end{array}$ & $\begin{array}{l}0.904^{* * *} \\
(0.0139)\end{array}$ \\
\hline Reference Dollar & & & $\begin{array}{l}0.000183^{* * *} \\
(0.0000531)\end{array}$ & $\begin{array}{l}0.000116^{* * *} \\
(0.0000291)\end{array}$ \\
\hline Employed & & & $\begin{array}{c}0.0366^{* *} \\
(0.0169)\end{array}$ & $\begin{array}{c}0.0295^{* *} \\
(0.0119)\end{array}$ \\
\hline BDM & & & $\begin{array}{c}-0.00339 \\
(0.0171)\end{array}$ & \\
\hline Average $\hat{\rho}$ & 1.115 & 0.987 & 1.409 & 1.382 \\
\hline \multicolumn{5}{|l|}{$\eta$ Estimation } \\
\hline Constant & $\begin{array}{l}6.822^{*} \\
(3.905)\end{array}$ & $\begin{array}{c}3.843^{*} \\
(1.973)\end{array}$ & $\begin{array}{l}4.571^{* *} \\
(2.187)\end{array}$ & $\begin{array}{l}12.72^{* *} \\
(5.194)\end{array}$ \\
\hline Reference Dollar & $\begin{array}{l}0.153^{* * *} \\
(0.0411)\end{array}$ & $\begin{array}{l}0.173^{* * *} \\
(0.0443)\end{array}$ & $\begin{array}{l}0.148^{* * *} \\
(0.0405)\end{array}$ & $\begin{array}{c}0.0292 \\
(0.0334)\end{array}$ \\
\hline Employed & $\begin{array}{l}-7.095^{*} \\
(3.812)\end{array}$ & $\begin{array}{c}-4.361^{* *} \\
(1.865)\end{array}$ & $\begin{array}{c}-4.763^{* *} \\
(2.036)\end{array}$ & $\begin{array}{c}1.582 \\
(6.182)\end{array}$ \\
\hline \multicolumn{5}{|l|}{$\mu$ Estimation } \\
\hline Constant & $\begin{array}{c}4.293^{* * *} \\
(1.513)\end{array}$ & $\begin{array}{c}3.219^{* * *} \\
(1.161)\end{array}$ & $\begin{array}{c}2.987^{* * *} \\
(1.121)\end{array}$ & $\begin{array}{c}3.024^{* * *} \\
(1.071)\end{array}$ \\
\hline Reference Dollar & $\begin{array}{l}0.107^{* * *} \\
(0.0147)\end{array}$ & $\begin{array}{l}0.109^{* * *} \\
(0.0159)\end{array}$ & $\begin{array}{l}0.105^{* * *} \\
(0.0175)\end{array}$ & $\begin{array}{l}0.105^{* * *} \\
(0.0154)\end{array}$ \\
\hline Employed & $\begin{array}{c}-3.681^{* * *} \\
(1.415)\end{array}$ & $\begin{array}{c}-2.720^{* *} \\
(1.074)\end{array}$ & $\begin{array}{c}-2.424^{* *} \\
(1.002)\end{array}$ & $\begin{array}{c}-2.411^{* *} \\
(0.959)\end{array}$ \\
\hline Observations & 5180 & 5180 & 5180 & 5180 \\
\hline Log Likelihood & -3091.2 & -3034.1 & -2946.0 & -2960.3 \\
\hline Subjects & 76 & 76 & 76 & 76 \\
\hline
\end{tabular}

Standard errors in parentheses are clustered at the subject level.

Constants for $\beta$ and $\delta$ are tested against 1 . All others are tested against 0 .

$\delta$ is the monthly discount factor. $\rho$ is the annual discount rate.

${ }^{*} p<0.10,{ }^{* *} p<0.05,{ }^{* * *} p<0.01$ 
Table 15: Maximum Likelihood Estimates, $\alpha=0.259$

\begin{tabular}{|c|c|c|c|c|}
\hline & $\begin{array}{c}(1) \\
\text { Model } 1\end{array}$ & $\begin{array}{c}(2) \\
\text { Model } 2\end{array}$ & $\begin{array}{c}(3) \\
\text { Model } 3\end{array}$ & $\begin{array}{c}(4) \\
\text { Model } 4\end{array}$ \\
\hline \multicolumn{5}{|l|}{$\beta$ Estimation } \\
\hline Constant & $\begin{array}{c}0.993^{*} \\
(0.00426)\end{array}$ & $\begin{array}{l}0.952^{* * *} \\
(0.0150)\end{array}$ & $\begin{array}{c}0.999 \\
(0.00333)\end{array}$ & $\begin{array}{c}0.985 \\
(0.0110)\end{array}$ \\
\hline Reference Dollar & & $\begin{array}{c}0.0000895^{*} \\
(0.0000459)\end{array}$ & & $\begin{array}{c}0.0000212 \\
(0.0000238)\end{array}$ \\
\hline Employed & & $\begin{array}{c}0.0406^{* * *} \\
(0.0139)\end{array}$ & & $\begin{array}{c}0.0199^{*} \\
(0.0105)\end{array}$ \\
\hline BDM & & $\begin{array}{c}0.000644 \\
(0.0125)\end{array}$ & & \\
\hline Average $\hat{\beta}$ & 0.993 & 0.984 & 0.999 & 0.996 \\
\hline \multicolumn{5}{|l|}{$\delta$ Estimation } \\
\hline Constant & $\begin{array}{c}0.988^{* * *} \\
(0.00240)\end{array}$ & $\begin{array}{c}0.988^{* * *} \\
(0.00242)\end{array}$ & $\begin{array}{c}0.977^{* * *} \\
(0.00343)\end{array}$ & $\begin{array}{c}0.975^{* * *} \\
(0.00384)\end{array}$ \\
\hline Reference Dollar & & & $\begin{array}{c}0.0000318^{* * *} \\
(0.0000100)\end{array}$ & $\begin{array}{l}0.0000287^{* * *} \\
(0.00000814)\end{array}$ \\
\hline Employed & & & $\begin{array}{c}0.00849^{* * *} \\
(0.00310)\end{array}$ & $\begin{array}{c}0.00795^{* * *} \\
(0.00298)\end{array}$ \\
\hline BDM & & & $\begin{array}{l}-0.00416 \\
(0.00449)\end{array}$ & \\
\hline Average $\hat{\rho}$ & 0.149 & 0.152 & 0.258 & 0.245 \\
\hline \multicolumn{5}{|l|}{$\eta$ Estimation } \\
\hline Constant & $\begin{array}{l}0.341^{* * *} \\
(0.0724)\end{array}$ & $\begin{array}{l}0.304^{* * *} \\
(0.0568)\end{array}$ & $\begin{array}{l}0.283^{* * *} \\
(0.0432)\end{array}$ & $\begin{array}{l}0.277^{* * *} \\
(0.0437)\end{array}$ \\
\hline Reference Dollar & $\begin{array}{c}-0.000368^{* *} \\
(0.000185)\end{array}$ & $\begin{array}{l}-0.000317^{*} \\
(0.000164)\end{array}$ & $\begin{array}{c}-0.000334^{* * *} \\
(0.0000961)\end{array}$ & $\begin{array}{c}-0.000330^{* * *} \\
(0.000100)\end{array}$ \\
\hline Employed & $\begin{array}{l}-0.0547 \\
(0.0886)\end{array}$ & $\begin{array}{l}-0.0251 \\
(0.0712)\end{array}$ & $\begin{array}{l}-0.0394 \\
(0.0475)\end{array}$ & $\begin{array}{c}-0.0274 \\
(0.0492)\end{array}$ \\
\hline \multicolumn{5}{|l|}{$\mu$ Estimation } \\
\hline Constant & $\begin{array}{l}0.212^{* * *} \\
(0.0336)\end{array}$ & $\begin{array}{l}0.200^{* * *} \\
(0.0269)\end{array}$ & $\begin{array}{l}0.183^{* * *} \\
(0.0248)\end{array}$ & $\begin{array}{l}0.173^{* * *} \\
(0.0215)\end{array}$ \\
\hline Reference dollar & $\begin{array}{l}0.0000720 \\
(0.000264)\end{array}$ & $\begin{array}{c}0.000131 \\
(0.000245)\end{array}$ & $\begin{array}{c}0.000132 \\
(0.000273)\end{array}$ & $\begin{array}{c}0.000293 \\
(0.000248)\end{array}$ \\
\hline Employed & $\begin{array}{c}-0.0885^{* *} \\
(0.0345)\end{array}$ & $\begin{array}{c}-0.0820^{* * *} \\
(0.0286)\end{array}$ & $\begin{array}{c}-0.0671^{* * *} \\
(0.0259)\end{array}$ & $\begin{array}{c}-0.0658^{* * *} \\
(0.0208)\end{array}$ \\
\hline Observations & 5180 & 5180 & 5180 & 5180 \\
\hline Log Likelihood & -1995.7 & -1953.1 & -1819.3 & -1816.3 \\
\hline Subjects & 76 & 76 & 76 & 76 \\
\hline
\end{tabular}

Standard errors in parentheses are clustered at the subject level.

Constants for $\beta$ and $\delta$ are tested against 1 . All others are tested against 0 .

$\delta$ is the monthly discount factor. $\rho$ is the annual discount rate.

${ }^{*} p<0.10,{ }^{* *} p<0.05,{ }^{* * *} p<0.01$ 
Table 16: Average Discounting Parameters by Magnitude of Reference Reward

\begin{tabular}{cccccc}
\hline \hline Reference Dollar & $\alpha$ & Average $\hat{\beta}$ & $\% \Delta$ Average $\hat{\beta}^{+}$ & Average $\hat{\rho}$ & $\% \Delta$ Average $\hat{\rho}^{+}$ \\
\hline 10 & 1 & 0.922 & - & 2.581 & - \\
100 & 1 & 0.982 & 6.51 & 1.772 & -31.34 \\
\hline 10 & 0.92 & 0.973 & - & 1.958 & - \\
100 & 0.92 & 0.986 & 1.34 & 1.45 & -25.95 \\
\hline 10 & 0.259 & 0.992 & - & 0.314 & - \\
100 & 0.259 & 0.996 & 0.40 & 0.256 & -18.47 \\
\hline \hline
\end{tabular}

Average $\hat{\beta}$ and Average $\hat{\rho}$ represent average fitted values from Model 4 ML Estimates.

$+\% \Delta$ in average fitted values for 100 dollar vs 10 dollar reference reward size.

Table 17: Random Coefficients Results

\begin{tabular}{|c|c|c|c|c|c|c|}
\hline & $\begin{array}{c}(1) \\
\text { Model } 1\end{array}$ & $\begin{array}{c}(2) \\
\text { Model } 2\end{array}$ & $\begin{array}{c}(3) \\
\text { Model } 1\end{array}$ & $\begin{array}{c}(4) \\
\text { Model } 2\end{array}$ & $\begin{array}{c}(5) \\
\text { Model } 1\end{array}$ & $\begin{array}{c}(6) \\
\text { Model } 2\end{array}$ \\
\hline$\alpha$ & 1 & 1 & 0.92 & 0.92 & 0.259 & 0.259 \\
\hline$\beta$ & & $\begin{array}{l}0.958^{* * *} \\
(0.0147)\end{array}$ & & $\begin{array}{c}0.961^{* * *} \\
(0.014)\end{array}$ & & $\begin{array}{c}0.985^{* *} \\
(0.00717)\end{array}$ \\
\hline$\delta$ Mean & $\begin{array}{c}0.924^{* * *} \\
(0.010)\end{array}$ & $\begin{array}{l}0.929^{* * *} \\
(0.0104)\end{array}$ & $\begin{array}{c}0.929^{* * *} \\
(0.00955)\end{array}$ & $\begin{array}{c}0.933^{* * *} \\
(0.00984)\end{array}$ & $\begin{array}{l}0.976^{* * *} \\
(0.0034)\end{array}$ & $\begin{array}{c}0.977^{* * *} \\
(0.00329)\end{array}$ \\
\hline$\delta$ S.D. & $\begin{array}{l}0.0451^{* * *} \\
(0.00479)\end{array}$ & $\begin{array}{l}0.0441^{* * *} \\
(0.00537)\end{array}$ & $\begin{array}{c}0.0406^{* * *} \\
(0.005)\end{array}$ & $\begin{array}{l}0.0397^{* * *} \\
(0.00552)\end{array}$ & $\begin{array}{c}0.00876^{* * *} \\
(0.00205)\end{array}$ & $\begin{array}{c}0.00798^{* * *} \\
(0.0030)\end{array}$ \\
\hline$\rho$ Mean & 1.573 & 1.430 & 1.415 & 1.292 & 0.34 & 0.318 \\
\hline$\eta$ & $\begin{array}{c}50.218^{* * *} \\
(15.471)\end{array}$ & $\begin{array}{c}47.178^{* * *} \\
(13.673)\end{array}$ & $\begin{array}{c}31.130^{* * *} \\
(8.586)\end{array}$ & $\begin{array}{c}29.227^{\text {*** }} \\
(7.712)\end{array}$ & $\begin{array}{l}0.373^{* * *} \\
(0.0627)\end{array}$ & $\begin{array}{c}0.35^{* * *} \\
(0.0618)\end{array}$ \\
\hline$\mu$ & $\begin{array}{c}7.591^{* * *} \\
(1.352)\end{array}$ & $\begin{array}{c}7.707^{* * *} \\
(1.50) \\
\end{array}$ & $\begin{array}{c}5.154^{* * *} \\
(0.931) \\
\end{array}$ & $\begin{array}{c}5.262^{* * *} \\
(1.028)\end{array}$ & $\begin{array}{l}0.137^{* * *} \\
(0.0202)\end{array}$ & $\begin{array}{l}0.148^{* * *} \\
(0.0332)\end{array}$ \\
\hline Observations & 5180 & 5180 & 5180 & 5180 & 5180 & 5180 \\
\hline Simulated LL & -2550.5 & -2542.9 & -2426.8 & -2419.8 & -1303.8 & -1297.8 \\
\hline Subjects & 76 & 76 & 76 & 76 & 76 & 76 \\
\hline
\end{tabular}

$\alpha$ is set exogenously.

Standard errors in parentheses are clustered at the subject level.

$\beta$ and $\delta$ Mean are tested against 1. All others are tested against 0.

$\delta$ is the monthly discount factor. $\rho$ is the annual discount rate.

${ }^{*} p<0.10,{ }^{* *} p<0.05,{ }^{* * *} p<0.01$ 


\section{Appendix A: Proofs of Incentive Compatibility}

Claim 1 Bidding one's true future valuation is a (weakly) dominant strategy for the BDM Mechanism.

Proof Let $\psi_{i t}$ be the discount factor for person $i$, time period $t$. Assume that $0<\psi_{i t}<1$. Also let $v_{i t}$ be person $i$ 's true present valuation of a prize to be received at time $t$. That is, $v_{i t}=x / \psi_{i t}$. Let $m_{i t}\left(v_{i t}\right)$ be the minimum amount at which person $i$ indicates they would accept a deferred reward to be received at time $t$ in lieu of an immediate reward of $\$ \mathrm{x}$. We need to show that $m_{i t}\left(v_{i t}\right)=v_{i t}=x / \psi_{i t}$ is a (weakly) dominant strategy. Denote the random draw amount as $d$. Denote the present value payoff to person $i$ from the mechanism as $\pi_{i}$.

Condition 1 Assume $m_{i t}\left(v_{i t}\right)>v_{i t}$.

Case $1 d<v_{i t}<m_{i t}\left(v_{i t}\right)$.

In this case, $i$ receives the immediate reward. The payoff is the same as if $i$ has bid $v_{i t}$.

$\pi_{i}=x$.

Case $2 d>m_{i t}\left(v_{i t}\right)>v_{i t}$.

In this case, $i$ receives the deferred reward. The payoff is the same as if $i$ had bid $v_{i t}$.

$\pi_{i}=\psi_{i t} * \underline{b}_{-i t}>\psi_{i t} * v_{i t}=x$.

Case $3 m_{i t}\left(v_{i t}\right)>d>v_{i t}$.

In this case, $i$ receives the immediate payment with a minimum willingness to accept the delayed reward of $m_{i t}\left(v_{i t}\right)$. So, $\pi_{i}=x$ if $m_{i t}\left(v_{i t}\right)>d$. If instead $i$ reveals their true valuation, they receive the delayed reward. $\pi_{i}=\psi_{i t} * d>\psi_{i t} * v_{i t}=x$ if $m_{i t}\left(v_{i t}\right)=v_{i t}$.

Thus, indicating a minimum willingness to accept of $v_{i t}$ weakly dominates bidding $m_{i t}\left(v_{i t}\right)$ when $m_{i t}\left(v_{i t}\right)>v_{i t}$.

Condition 2 Assume $m_{i t}\left(v_{i t}\right)<v_{i t}$

Case $4 m_{i t}\left(v_{i t}\right)<v_{i t}<d$. 
In this case, $i$ receives the deferred payoff. The payoff is the same as if $i$ had revealed $v_{i t}$.

$$
\pi_{i}=\psi_{i t} * d>\psi_{i t} * v_{i t}=x .
$$

Case $5 d<m_{i t}\left(v_{i t}\right)<v_{i t}$

In this case, $i$ receives the immediate reward, which would also result by revealing the true valuation of $v_{i t}$.

$$
\pi_{i}=x .
$$

Case $6 m_{i t}\left(v_{i t}\right)<d<v_{i t}$

In this case, $i$ receives the delayed reward.

$$
\pi_{i}=\psi_{i t} * d<\psi_{i t} * v_{i t}=x \text { if } m_{i t}\left(v_{i t}\right)<v_{i t} .
$$

If instead $i$ reveals their true valuation, they receive the immediate reward.

$$
\pi_{i}=x \text { if } m_{i t}\left(v_{i t}\right)=v_{i t} .
$$

Thus, revealing a true minimum willingness to accept the delayed reward of $v_{i t}$ weakly dominates indicating $m_{i t}\left(v_{i t}\right)$ when $m_{i t}\left(v_{i t}\right)<v_{i t}$.

Therefore, revealing $v_{i t}$ weakly dominates indicating $m_{i t}\left(v_{i t}\right) \neq v_{i t}$.

Claim 2 Bidding one's true future valuation is a (weakly) dominant strategy for the 2PSB auction.

Proof. Let $\psi_{i t}$ be the discount factor for person $i$, time period $t$. Assume that $0<\psi_{i t}<1$. Also let $v_{i t}$ be person $i$ 's true present valuation of a prize to be received at time $t$. That is, $v_{i t}=x / \psi_{i t}$. Let $b_{i t}\left(v_{i t}\right)$ be the bid for person $i$ on a deferred reward to be received at time $t$. We need to show that $b_{i t}\left(v_{i t}\right)=v_{i t}=x / \psi_{i t}$ is a (weakly) dominant strategy. Denote the lowest other bid in the auction as $\underline{b}_{-i t}$. Denote the present value payoff to person $i$ from the auction as $\pi_{i}$.

Condition 3 Assume $b_{i t}\left(v_{i t}\right)>v_{i t}$.

Case $7 \underline{b}_{-i t}<v_{i t}<b_{i t}\left(v_{i t}\right)$.

In this case, $i$ doesn't win the auction and the result is the same as bidding $v_{i t}$. $\pi_{i}=x$.

Case $8 \underline{b}_{-i t}>b_{i t}\left(v_{i t}\right)>v_{i t}$. 
In this case, $i$ wins the deferred payoff. The payoff is the same as if $i$ had bid $v_{i t}$. $\pi_{i}=\psi_{i t} * \underline{b}_{-i t}>\psi_{i t} * v_{i t}=x$.

Case $9 b_{i t}\left(v_{i t}\right)>\underline{b}_{-i t}>v_{i t}$.

In this case, $i$ loses with the auction with a bid of $b_{i t}\left(v_{i t}\right)$.

$\pi_{i}=x$ if $b_{i t}\left(v_{i t}\right)>v_{i t}$.

If instead $i$ bids their true valuation, they win the auction.

$\pi_{i}=\psi_{i t} * \underline{b}_{-i t}>\psi_{i t} * v_{i t}=x$ if $b_{i t}\left(v_{i t}\right)=v_{i t}$.

Thus, bidding $v_{i t}$ weakly dominates bidding $b_{i t}\left(v_{i t}\right)$ when $b_{i t}\left(v_{i t}\right)>v_{i t}$.

Condition 4 Assume $b_{i t}\left(v_{i t}\right)<v_{i t}$

Case $10 b_{i t}\left(v_{i t}\right)<v_{i t}<\underline{b}_{-i t}$.

In this case, $i$ wins the deferred payoff. The payoff is the same as if $i$ had bid $v_{i t}$. $\pi_{i}=\psi_{i t} * \underline{b}_{-i t}>\psi_{i t} * v_{i t}=x$.

Case $11 \underline{b}_{-i t}<b_{i t}\left(v_{i t}\right)<v_{i t}$

In this case, $i$ doesn't win the auction. They wouldn't have won with a bid of $v_{i t}$ either.

$\pi_{i}=x$.

Case $12 b_{i t}\left(v_{i t}\right)<\underline{b}_{-i t}<v_{i t}$

In this case, $i$ wins the auction.

$\pi_{i}=\psi_{i t} * \underline{b}_{-i t}<\psi_{i t} * v_{i t}=x$ if $b_{i t}\left(v_{i t}\right)<v_{i t}$.

If instead $i$ bids their true valuation, they don't win the auction.

$\pi_{i}=x$ if $b_{i t}\left(v_{i t}\right)=v_{i t}$.

Thus, bidding $v_{i t}$ weakly dominates bidding $b_{i t}\left(v_{i t}\right)$ when $b_{i t}\left(v_{i t}\right)<v_{i t}$.

Therefore, bidding $v_{i t}$ weakly dominates bidding $b_{i t}\left(v_{i t}\right) \neq v_{i t}$.

\section{Appendix B: Sample 2PSB Script}

In this market, the objects being traded are future cash payouts. You have been given $\$ 100$. You have the opportunity to trade this $\$ 100$ for a cash payout to be paid three months from now. 
Please indicate the lowest dollar amount of cash to be received three months from now for which you would be willing to trade your $\$ 100$.

This is your bid amount.

I will then rank the bids for all players from lowest to highest. The player with the lowest bid for the future cash payout wins the auction for this round. They will win the future cash payout, equal to the amount of the second lowest bid for this round in exchange for their $\$ 100$.

If you do not win the auction, no exchange will be made. If you do win the auction, you will have to trade your $\$ 100$ for the future cash payout (equal to the second lowest bid from this auction round). If you do not win the auction you will keep your $\$ 100$ and you will not receive any future payout.

Notice the following three things:

(1) It is in your best interest to bid an amount equal to your true value of the future cash payout.

(2) You would not want to bid an amount lower than your true value because you may then win the auction and have to accept a future cash payout amount that is less than your true value in exchange for your $\$ 100$.

(3) You would not want to bid an amount higher than your true value because you may then lose the auction in a case where you would have won the auction if you had bid your true value and received a future cash payout amount that is greater than your true value.

\section{Appendix C: Sample BDM Script}

You have the chance to receive $\$ 100$ today or another sum of money six months from today. Please indicate for which dollar amounts you would choose to receive the delayed reward (and no payment today), and for which dollar amounts you would choose to receive $\$ 100$ today (and no future payments).

Ask yourself for each of the dollar amounts listed, "If I had the chance to receive _____- six months from now and no money today, or $\$ 100$ today and no money in the future, which option would I choose?"

After you have made your selections I will randomly select one dollar amount to determine the amount of the delayed reward. If you have indicated that you would choose the delayed reward at that dollar amount I will pay you the selected dollar amount six months from now. If you have indicated that you would not choose the delayed reward at that dollar amount I will pay you $\$ 100$ today. 
Notice the following two things:

(1) Your decision can have no effect on the future reward amount actually used because the reward amount will be selected at random.

(2) It is in your interest to indicate your true preferences at each of the possible rewards listed below.

Delayed Reward Future Payment Option ${ }^{27} \quad$ Immediate $\$ 100$ Payment Option ${ }^{28}$

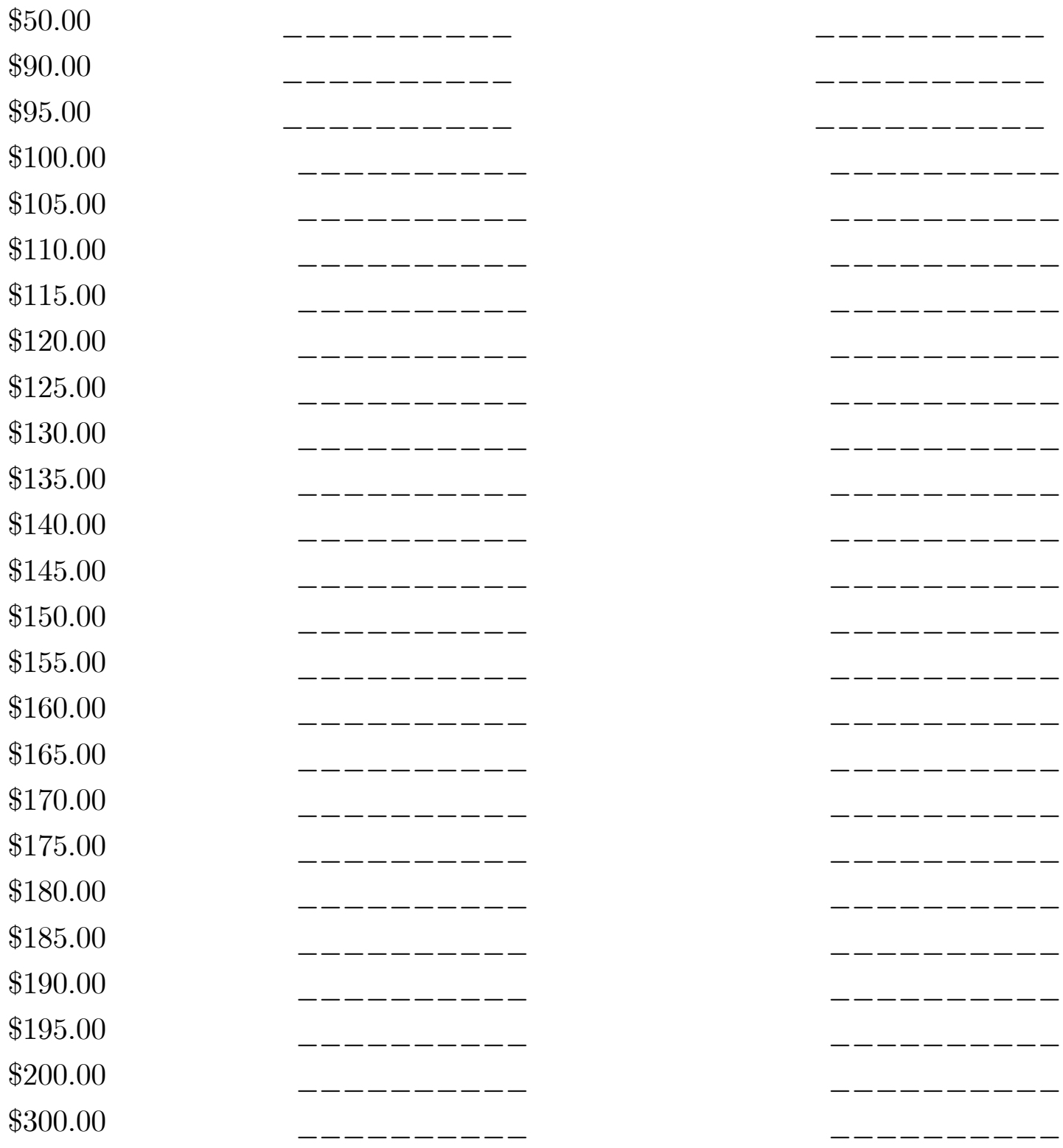

\footnotetext{
${ }^{27}$ The actual survey script had additional verbage in this location reading, "I would take this amount 6 months from now instead of $\$ 100$ today."

${ }^{28}$ The actual survey script had additional verbage in this location reading, "I would not take this amount 6 months from now instead of $\$ 100$ today."
} 
$\$ 400.00$

$\$ 500.00$

\section{Appendix D: MLE Results for Varying Assump- tions on Background Consumption}

Table 18: MLE Results for Varying Background Consumption

\begin{tabular}{ccccc}
\hline \hline$\alpha$ & $\omega$ & Model & Average $\hat{\beta}$ & Average $\hat{\rho}$ \\
\hline 0.259 & 5 & 1 & 0.988 & 0.22 \\
0.259 & 10 & 1 & 0.986 & 0.243 \\
0.259 & 15 & 1 & 0.985 & 0.26 \\
0.259 & 20 & 1 & 0.984 & 0.275 \\
0.259 & 5 & 4 & 0.994 & 0.447 \\
0.259 & 10 & 4 & 0.993 & 0.517 \\
0.259 & 15 & 4 & 0.993 & 0.57 \\
0.259 & 20 & 4 & 0.992 & 0.615 \\
0.92 & 5 & 1 & 0.98 & 1.133 \\
0.92 & 10 & 1 & 0.98 & 1.145 \\
0.92 & 15 & 1 & 0.98 & 1.152 \\
0.92 & 20 & 1 & 0.98 & 1.158 \\
0.92 & 5 & 4 & 1.013 & 1.486 \\
0.92 & 10 & 4 & 1.013 & 1.503 \\
0.92 & 15 & 4 & 1.013 & 1.516 \\
0.92 & 20 & 4 & 1.012 & 1.527 \\
\hline \hline
\end{tabular}

$\omega$ is the assumed level of background consumption.

Results are from maximum likelihood Models 1 and 4 . 